\title{
Spatial and temporal variability of snowfall over Greenland from CloudSat observations
}

\author{
Ralf Bennartz ${ }^{1,2}$, Frank Fell ${ }^{3}$, Claire Pettersen ${ }^{2}$, Matthew D. Shupe ${ }^{4}$, and Dirk Schuettemeyer ${ }^{5}$ \\ ${ }^{1}$ Earth and Environmental Sciences Department, Vanderbilt University, Nashville, Tennessee, USA \\ ${ }^{2}$ Space Science and Engineering Center, University of Wisconsin - Madison, Madison, Wisconsin, USA \\ ${ }^{3}$ Informus GmbH, Berlin, Germany \\ ${ }^{4}$ Physical Sciences Division, Cooperative Institute for Research in Environmental Science and \\ NOAA Earth System Research Laboratory, Boulder, Colorado, USA \\ ${ }^{5}$ ESA ESTEC, Noordwijk, the Netherlands
}

Correspondence: Ralf Bennartz (ralf.bennartz@vanderbilt.edu)

Received: 30 September 2018 - Discussion started: 7 January 2019

Revised: 15 April 2019 - Accepted: 22 May 2019 - Published: 21 June 2019

\begin{abstract}
We use the CloudSat 2006-2016 data record to estimate snowfall over the Greenland Ice Sheet (GrIS). We first evaluate CloudSat snowfall retrievals with respect to remaining ground-clutter issues. Comparing CloudSat observations to the GrIS topography (obtained from airborne altimetry measurements during IceBridge) we find that at the edges of the GrIS spurious high-snowfall retrievals caused by ground clutter occasionally affect the operational snowfall product. After correcting for this effect, the height of the lowest valid CloudSat observation is about $1200 \mathrm{~m}$ above the local topography as defined by IceBridge. We then use ground-based millimeter wavelength cloud radar (MMCR) observations obtained from the Integrated Characterization of Energy, Clouds, Atmospheric state, and Precipitation at Summit, Greenland (ICECAPS) experiment to devise a simple, empirical correction to account for precipitation processes occurring between the height of the observed CloudSat reflectivities and the snowfall near the surface. Using the height-corrected, clutter-cleared CloudSat reflectivities we next evaluate various $Z-S$ relationships in terms of snowfall accumulation at Summit through comparison with weekly stake field observations of snow accumulation available since 2007. Using a set of three $Z-S$ relationships that best agree with the observed accumulation at Summit, we then calculate the annual cycle snowfall over the entire GrIS as well as over different drainage areas and compare the derived mean values and annual cycles of snowfall to ERA-Interim reanalysis. We find the annual mean snowfall over the GrIS in-
\end{abstract}

ferred from CloudSat to be $34 \pm 7.5 \mathrm{~cm} \mathrm{yr}^{-1}$ liquid equivalent (where the uncertainty is determined by the range in values between the three different $Z-S$ relationships used). In comparison, the ERA-Interim reanalysis product only yields $30 \mathrm{~cm} \mathrm{yr}^{-1}$ liquid equivalent snowfall, where the majority of the underestimation in the reanalysis appears to occur in the summer months over the higher GrIS and appears to be related to shallow precipitation events. Comparing all available estimates of snowfall accumulation at Summit Station, we find the annually averaged liquid equivalent snowfall from the stake field to be between 20 and $24 \mathrm{~cm} \mathrm{yr}^{-1}$, depending on the assumed snowpack density and from CloudSat $23 \pm 4.5 \mathrm{~cm} \mathrm{yr}^{-1}$. The annual cycle at Summit is generally similar between all data sources, with the exception of ERAInterim reanalysis, which shows the aforementioned underestimation during summer months.

\section{Introduction}

The Greenland Ice Sheet (GrIS) is currently losing mass at a rate of roughly $240 \mathrm{Gt} \mathrm{yr}^{-1}$, translating into a sea level rise of $0.47 \pm 0.23 \mathrm{~mm} \mathrm{yr}^{-1}$ (van den Broeke et al., 2016), which corresponds to roughly $15 \%-20 \%$ of the total annual mean sea level rise. Precipitation is the sole source of mass of the GrIS. Additionally, the inter-annual precipitation variability appears to be the main driver of inter-annual variability in the mass balance of the GrIS (van den Broeke et al., 2009). 
It is also the largest source of uncertainty in the surface mass balance of the GrIS (van den Broeke et al., 2009). At the same time, ground-based long-term observations of precipitation over the GrIS are sparse. Over the GrIS surface station networks include the Greenland Climate Network (GCNET; Box and Steffen, 2000) and the Programme for Monitoring of the Greenland Ice Sheet (PROMICE; by the Danish Energy Agency; van As, 2017). These networks of surface stations do not directly observe precipitation; however limited information on accumulation may be inferred by boom height measurements using sonic ranging. Van den Broeke et al. (2016) point out the importance of individual mass sources, i.e., snowfall, contributing to the GrIS surface mass balance which " $[\ldots]$ must be interpolated from scarce in situ measurements and/or simulated using dedicated regional climate models, which introduces potentially large uncertainties". Comparison studies of different climate and reanalysis models show an about $25 \%-40 \%$ spread in snowfall estimates over the GrIS between the different models (Cullather et al., 2014; Vernon et al., 2013).

Since 2006, CloudSat observations have been used in a series of studies addressing snowfall globally (Liu, 2008; Hiley et al., 2011; Palerme et al., 2014; Kulie et al., 2016; Adhikari et al., 2018; Kulie and Milani, 2018). While some of the global studies include Greenland, a detailed assessment of snowfall over the GrIS using CloudSat has to our knowledge not yet been performed. Here we present such an assessment.

Several factors complicate snowfall estimates from CloudSat over the GrIS. First, the height of the central GrIS makes for a unique environment in terms of snowfall characteristics. For example, Pettersen et al. (2018) find that a large fraction of the total accumulation at Summit Station falls from clouds that contain no liquid water with only ice microphysical processes involved. Secondly, the steep altitude changes at the edges of the ice sheet pose challenges to the spaceborne radar observations due to ground clutter. This issue has a compounding impact on CloudSat's clutter-affected blind zone near the surface, which typically extends from the surface to about $1200 \mathrm{~m}$ (Maahn et al., 2014). Thus, "surface" snowfall rates observed from CloudSat are typically taken at an altitude of $1200 \mathrm{~m}$ above the surface.

To account for the above issues related to surface topography and CloudSat's blind zone, we use auxiliary information about the GrIS surface topography (the IceBridge BedMachine V3 topography; Morlighem et al., 2017) to better characterize which CloudSat radar bin can be regarded as the lowest clutter-free observation. We then use millimeter wavelength cloud radar (MMCR) observations from ICECAPS to estimate the impact of CloudSat's observation height on estimated surface snowfall, and we propose a simple GrISspecific empirical correction to account for the difference between actual surface snowfall and the CloudSat observations made at about $1200 \mathrm{~m}$ height above the surface. We further use ground-based snowfall accumulation from Summit Station to assess the validity of different $Z-S$ relationships ap- plied to CloudSat. Based on these corrections and findings, we then calculate our best estimates of surface snowfall from all available CloudSat observations and assess the annual cycle and spatial distribution of snowfall over the entire GrIS.

The remainder of this paper is structured as follows: in Sect. 2 we discuss the different data source including the ground-based observations at Summit Station, CloudSat satellite observations, and reanalysis products. Section 3 addresses the aforementioned issues related to using CloudSat as a proxy for surface snowfall. In Sect. 4 we compare CloudSat and ERA-Interim reanalysis data products and provide estimates for the annual cycle of snowfall over the different drainage systems of the GrIS as well as over Summit. Conclusions and an outlook are provided in Sect. 5.

\section{Datasets and methods}

\subsection{CloudSat data}

CloudSat (Stephens et al., 2002, 2008) carries the singlefrequency, W-band $(94 \mathrm{GHz})$ cloud-profiling radar (CPR; Tanelli et al., 2008). The CPR has provided global cloud and precipitation profiles since 2006; however, only daytime scenes can be observed since 2011 due to a hardware failure ${ }^{1}$. The CPR is a non-scanning, near-nadir pointing instrument with a mean spatial resolution of $\sim 1.5 \mathrm{~km}$ and a vertical range gate spacing of $500 \mathrm{~m}$, although instrument oversampling enables $240 \mathrm{~m}$ data bins in the CloudSat data products. In the framework of this study, we use the 2C-SNOW-PROFILE (Wood et al., 2014) together with the GEOPROF reflectivity profiles and ECMWF-AUX temperature and moisture profiles (Stephens et al., 2008). Product documentation can be obtained from the CloudSat Data Processing Center (DPC, http://www.cloudsat.cira.colostate. edu/, last access: 9 June 2019). All analysis is based on the CloudSat Release 5 data, which were made publicly available by the DPC in June 2018.

Figure 1 shows the number of CloudSat measurements available over Greenland (top) and within a $50 \mathrm{~km}$ range from Summit Station (bottom). One can clearly identify the reduction in data coverage after the CloudSat battery failure in April 2011. Even after operations were restored, data collection was limited to the sunlit part of the orbit, leading to an annual cycle in the number of observations available over Greenland.

Figure 2 shows the spatial distribution of these measurements over Greenland. Because of CloudSat's $16 \mathrm{~d}$ repeat pattern, coverage at high spatial resolution creates a diamond-shaped pattern over Greenland, as can be seen in Fig. 2b. This pattern limits the maximum resolution of any climatology based on CloudSat data. For a resolution of

\footnotetext{
${ }^{1}$ For a detailed timeline of CloudSat availability, see the operational CloudSat Radar Status blog at https://cloudsat.atmos. colostate.edu/news/CloudSat_status (last access: 9 June 2019).
} 

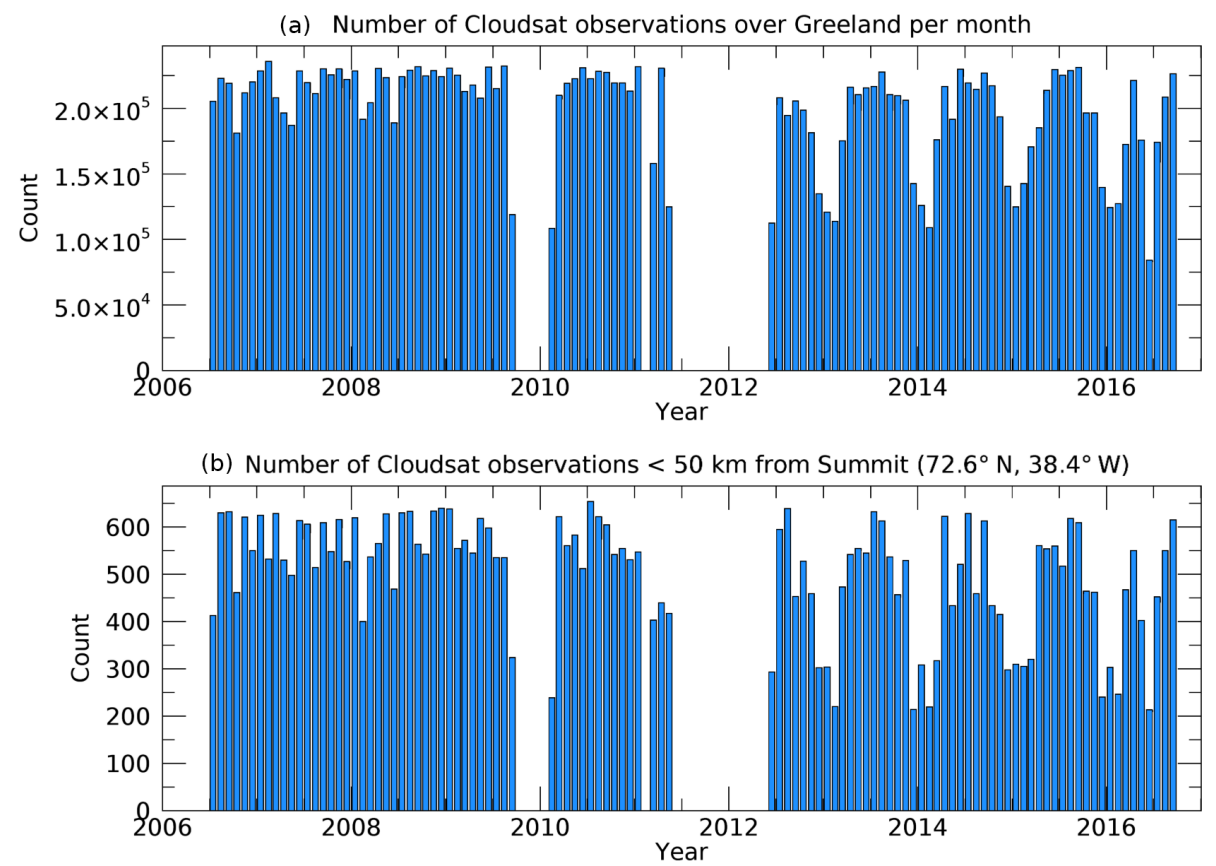

Figure 1. Number of CloudSat observations per month all over Greenland (a) and within $50 \mathrm{~km}$ of Summit Station (b).

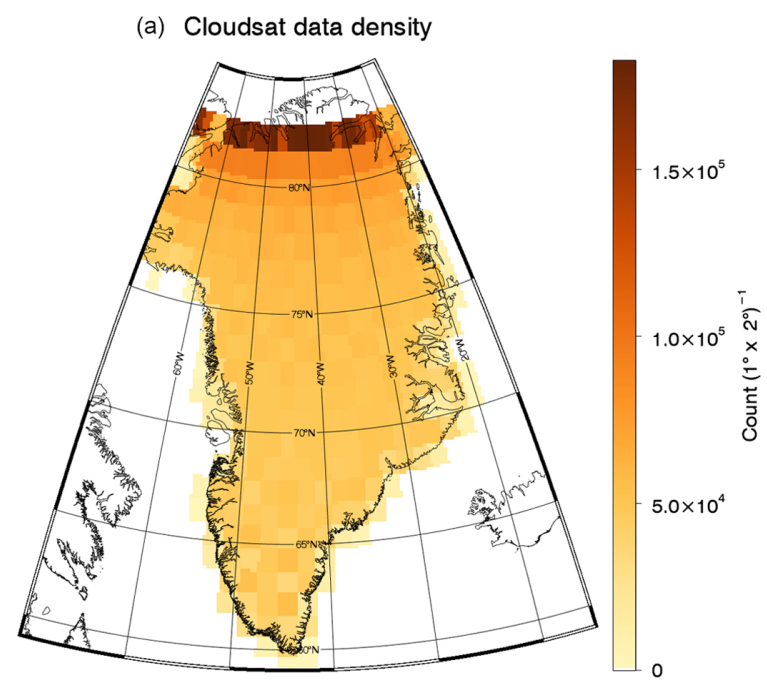

(b) Cloudsat data density

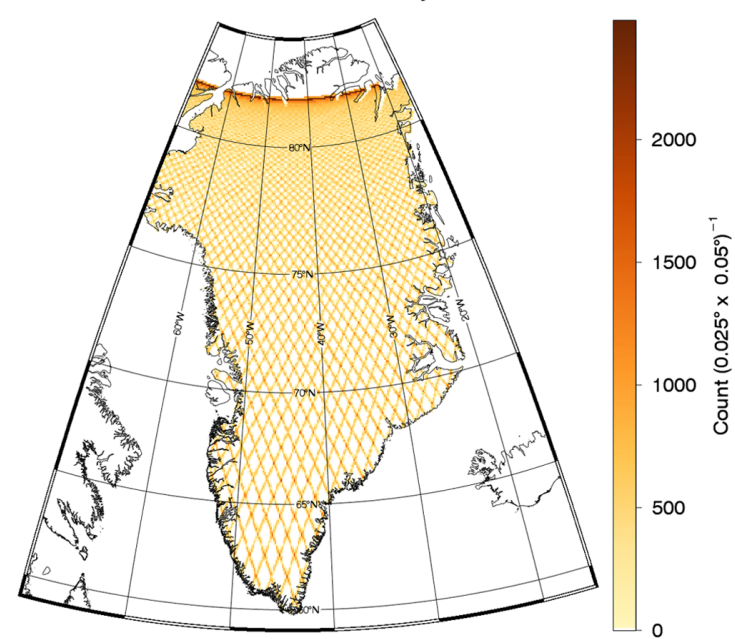

Figure 2. CloudSat data density over Greenland at $1^{\circ} \times 2^{\circ}$ (a, corresponding to $100 \mathrm{~km} \times 100 \mathrm{~km}$ at $\left.60^{\circ} \mathrm{N}\right)$ and $0.025^{\circ} \times 0.05^{\circ}(\mathbf{b}$, corresponding to $2.5 \mathrm{~km} \times 2.5 \mathrm{~km}$ at $60^{\circ} \mathrm{N}$ ). Shown is the total number of observations per grid box over the time period from 2006 to 2016 .

roughly $100 \mathrm{~km} \times 100 \mathrm{~km}$, the coverage appears fairly uniform apart from a north-south gradient, which is a result of the better coverage near the maximum coverage latitude around $81.8^{\circ}$, due to CloudSat's inclination of about $98.2^{\circ}$.

\subsection{ICECAPS observations}

The ICECAPS (Integrated Characterization of Energy, Clouds, Atmospheric state, and Precipitation at Summit) experiment operates a sophisticated suite of instruments that observe properties of the atmosphere, clouds, and precipita- tion at Summit Station, located near the apex of the GrIS at an elevation of $3200 \mathrm{~m}$ above sea level (Shupe et al., 2013). These instruments have been in operation at the NSF Mobile Science Facility nearly continuously since July 2010. This comprehensive dataset of atmospheric properties above the GrIS is unprecedented, due to both the large number of distinct and complementary measurements that are being made and the length of the time series.

The ICECAPS experiment, as well as instrument specifications, measurements, and derived products, are described 
in Shupe et al. (2013). In particular, the Ka-band MMCR, the X-band Precipitation Occurrence Sensor System (POSS), and the Multi-Angle Snowflake Camera (MASC, 20152016, selected dates only) are of relevance with respect to precipitation. In this study we build on earlier work by Castellani et al. (2015) and Pettersen et al. (2018). The latter study also provides a combined dataset of relevant parameters for studying precipitation variability over the central GrIS. This dataset is available with a temporal resolution of $1 \mathrm{~min}$ and is used as a basis for the investigations performed here but complemented with additional MMCR observations. For more details on the MMCR and its calibration, see Castellani et al. (2015) and references therein.

In addition to these ICECAPS data, other observations are available at Summit Station. Most important in this context is the so-called "snow stake field", which consists of $11 \times 11$ bamboo stakes planted in a square a few hundred meters away from the station. The height of all 121 stakes above the snow surface is read off approximately every week, thereby creating a unique reference for surface height changes. Once a year, the stakes are raised by about $70 \mathrm{~cm}$ in order to allow for continuous measurements. The stake measurements go back to 2003, with easily accessible data going back to 2007, covering the full ICECAPS period, and providing an independent set of observations of snowfall accumulation. Similar to Castellani et al. (2015), who provide a discussion on the accuracy of the stake field data, we herein use these stake observations to assess the other accumulation measurements, namely from the ground-based and space-borne radar. Castellani et al. (2015) address the importance of blowing snow as a source of noise for individual stake field observations and suggest using the average of all 121 individual stakes as an estimate or the actual accumulation. We follow their approach. They further discuss existing literature on the importance of blowing snow over the GrIS and indicate that the net effect of blowing snow is small (see Cullen et al., 2014).

\subsection{ERA-Interim}

ERA-Interim (Dee et al., 2011) is a third-generation global atmospheric reanalysis provided by the European Centre for Medium-Range Weather Forecasts (ECMWF). It expands on previous versions (e.g., ERA-40) by using an improved atmospheric model and assimilation system (ECMWF, 4DVAR, 2006). The spatial resolution of the dataset is approximately $80 \mathrm{~km}$ (T255 spectral) on 60 vertical levels from the surface up to $0.1 \mathrm{hPa}$. Among other data, it assimilates data from a number of satellites. ERA-Interim data are available since 1979 and are continuously updated. For this study, monthly gridded snowfall estimates were used (downloaded from https://rda.ucar.edu/datasets/ds627.0/, last access: 9 June 2019).

\section{$2.4 Z-S$ relations used in this study}

To compare CloudSat CPR and the MMCR, we apply a set of different published $Z-S$ relationships as well as $Z-S$ relationships empirically fitted to some of the observational data. The $Z-S$ relationships used are summarized in Table 1. In addition to the Matrosov (2007, hereafter M07) relationship used in various previous studies, we employ a set of $Z-S$ relationships that apply to single habits, which, based on the above considerations and observations, might be better proxies for snowfall at Summit than M07. While some $Z-S$ relationships are only available at Ka band (i.e., MMCR), others are available only at $\mathrm{W}$ band (i.e., CloudSat). Only four $Z_{-}$ $S$ relationships are available consistently for both Ka and W band and, therefore, allow transferring results between the two bands. Uncertainties of instantaneous snowfall retrievals using $Z-S$ relationships can be large and are discussed in detail in the publications referenced in the last column of Table 1 . The individual uncertainties should not be confused with systematic errors introduced by the choice of particular $Z-S$ relationships. Such systematic errors are of greater importance when generating climatological precipitation estimates (as random uncertainties average out in the process of generating, e.g., monthly means). Here we follow an approach developed in our earlier publications (Kulie and Bennartz, 2009; Hiley et al., 2011), where we define uncertainties on the climatological end product in terms of differences between different $Z-S$ relationships. We believe that this approach provides more realistic error estimates on climatological products (for more details, see Hiley et al., 2011).

\subsection{Assumption on snowpack density used in this study}

Dibb and Fahnestock (2004), based on snow pits, find snow densities over central Greenland between 240 and $370 \mathrm{~kg} \mathrm{~m}^{-3}$ at depths between 15 and $45 \mathrm{~cm}$, which is probably a realistic average depth range for annual accumulation studies. More recent results by Fausto et al. (2018) indicate an average density of the uppermost snow layer over Greenland to be $315 \pm 44 \mathrm{~kg} \mathrm{~m}^{-3}$ for the uppermost $10 \mathrm{~cm}$ and $341 \pm 37 \mathrm{~kg} \mathrm{~m}^{-3}$ for the uppermost $50 \mathrm{~cm}$. Fausto et al. (2018), as well as earlier studies (e.g., Reeh et al., 2005), also find a weak dependency of density on temperatures. Here we use snowpack density in two ways: firstly, in Sect. 3.4.2 we use the stake field observations as a reference to assess the validity of different CloudSat-based $Z-S$ relationships. Following the work of Castellani et al. (2015), we compared the stake field data with CloudSat-based liquid equivalent snowfall rates by calculating the effective density needed for the CloudSat snowfall estimates to match the observed accumulation. We then reject as unrealistic $Z-S$ relationships that fall outside the above wide range of densities reported for Summit. Secondly, in Sect. 4.2 we compare the annual cycle of liquid equivalent snowfall over Summit from different observations. To convert the stake field values into 
Table 1. Parameters of Ka-band (MMCR) $Z-S$ relations and $\mathrm{W}$ band (CloudSat) used in this study. The POSS operates at $\mathrm{X}$ band so that the $Z-S$ relation is not directly comparable to the $Z-S$ relations for MMCR. A $Z-S$ relationship is defined as $Z=A S^{B}$ where $S$ is the snowfall rate (in $\mathrm{mm} \mathrm{h}^{-1}$ ) and $Z$ the radar reflectivity (in $\mathrm{mm}^{6} \mathrm{~m}^{-3}$ ).

\begin{tabular}{|c|c|c|c|c|c|}
\hline Name & $A$ (Ka band) & $B$ (Ka band) & $A(\mathrm{~W}$ band $)$ & $B$ (W band $)$ & Reference \\
\hline M07 & 56.0 & 1.20 & 10.0 & 0.80 & $\begin{array}{l}\text { Castellani et al. (2015), Matrosov (2007), } \\
\text { Pettersen et al. (2018) }\end{array}$ \\
\hline KB09_LR3 & 24.0 & 1.51 & 13.2 & 1.40 & $\begin{array}{l}\text { Kulie and Bennartz (2009), using Liu (2008) } \\
\text { three-bullet rosettes }\end{array}$ \\
\hline KB09_HA & 313.3 & 1.85 & 56.4 & 1.52 & $\begin{array}{l}\text { Kulie and Bennartz (2009), using Hong (2007) } \\
\text { aggregates }\end{array}$ \\
\hline L08 & - & - & 11.5 & 1.25 & Liu $(2008)$ \\
\hline HI11_L & - & - & 7.6 & 1.30 & Hiley et al. (2011) \\
\hline HI11_A & - & - & 21.6 & 1.20 & Hiley et al. (2011) \\
\hline HI11_H & - & - & 61.2 & 1.10 & Hiley et al. (2011) \\
\hline POSS & $\mathrm{n} / \mathrm{a}$ & $\mathrm{n} / \mathrm{a}$ & - & - & Pettersen et al. (2018), Sheppard and Joe (2008) \\
\hline
\end{tabular}

liquid equivalent snowfall we use the conversions proposed by Fausto et al. (2018) and Reeh et al. (2005) to provide a range of liquid equivalent snowfall rates based on the stake field observations.

\section{Evaluation of CloudSat observations}

Here we assess the full CloudSat snowfall dataset over Greenland in terms of its viability for climatological snowfall studies. Amount and spatial distribution of the data used for this assessment are shown in Figs. 1 and 2. We analyze the dataset with respect to the following issues:

a Effects and removal of ground clutter.

b. Impact of height of CloudSat observation above the surface.

c. Impact of choice of $Z-S$ relationship.

At Summit, concurrent observations from the snow stake field and MMCR allow for a detailed assessment of these issues.

\subsection{Effects and removal of ground clutter}

CloudSat observations in the lowest range bins above the surface are affected by ground clutter. Because of topography, this effect is more pronounced over land than over ocean. The CloudSat SNOWPROF product accounts for the impact of ground clutter by providing a confidence flag for the retrieved surface snowfall rates. This flag depends on the type of surface as well as on other criteria, such as vertical consistency of retrieved snowfall rates. A key input over the highly structured coastal terrain of Greenland and the edges of the GrIS is the height of the surface bin, which describes where the radar beam first interacts with the surface. This quantity is provided in the CloudSat data and is retrieved from the radar reflectivity itself, as well as from an underlying digital elevation model.

In our analysis, we found that the height of the surface bin is not always accurately represented over Greenland. This occasionally causes significant outliers in the retrieved surface snowfall rate. In order to study and possibly correct for this issue, we use the IceBridge BedMachine (V3) surface topography measurements (Morlighem et al., 2017) and collocate those with each individual CloudSat observation. We then re-derive the snowfall rates based on the fifth radar bin above the surface as defined by this new topography. We compare these new retrievals to the originally retrieved snowfall rates, which also typically are taken from the fifth radar bin above the surface, but with a different prescribed surface elevation model defining the surface. We restrict our analysis to SNOWPROF confidence flag values 3 and 4, which indicate high confidence in the retrieval.

The difference in elevation reported between CloudSat and BedMachine can be seen in Fig. 3. It is not entirely unrealistic that some of the differences seen between the two digital elevation models may be caused by melting in the ablation zone. However, differences might also be caused by other factors. Clearly, some of the coastal regions with the largest differences experience significant amounts of snowfall. The impact of using different underlying surface topographies for snowfall retrieval and accumulation is shown in Figs. 4 through 6.

Figure 4 shows two-dimensional histograms of radar reflectivity and derived SNOWPROF surface snowfall rate. For each reported snowfall rate, the corresponding radar reflectivity was obtained from the CloudSat GEOPROF product. Figure 4a shows the surface snowfall rate and reflectivity reported directly from the product. Figure $4 \mathrm{~b}$ shows the revised snowfall rate accounting for the BedMachine topography. Note that for Fig. 4b all snowfall rates are also directly retrieved from SNOWPROF. In contrast to Fig. 4a, the snowfall rates are occasionally taken from radar bins higher in the 
(a) CloudSat surface elevation

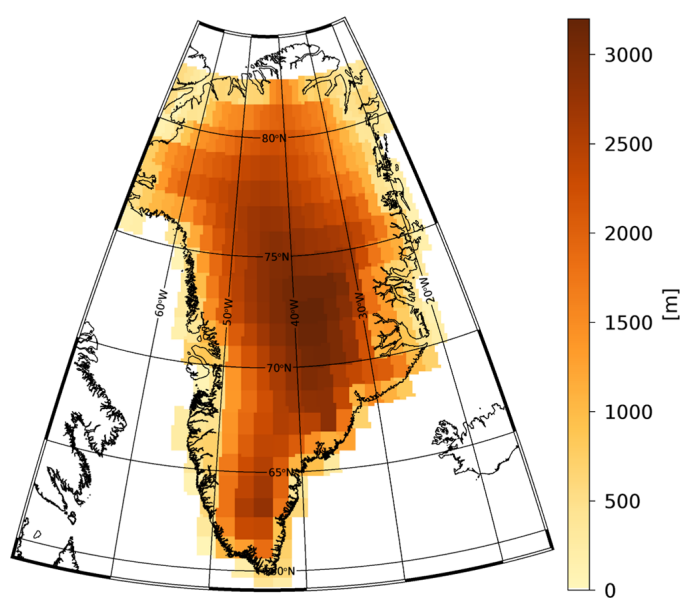

(b) Difference elevation (BedMachine - CloudSat)

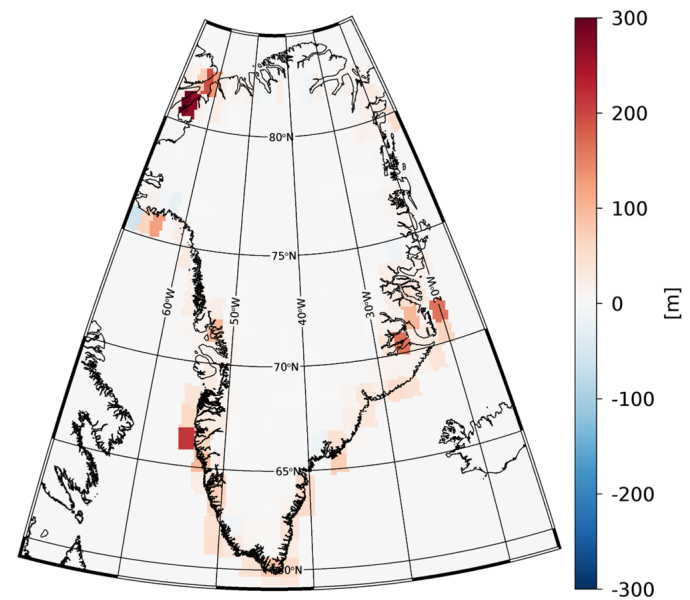

Figure 3. Panel (a) shows the mean elevation reported from CloudSat binned to $1^{\circ} \times 2^{\circ}$. Panel (b) shows the difference between the elevation difference between IceBridge BedMachine v3 (Morlighem et al., 2017) and CloudSat. Note that open water and sea ice observations are excluded from the dataset, so that differences observed near the coast only stem from ice-free land or GrIS observations within each grid box.
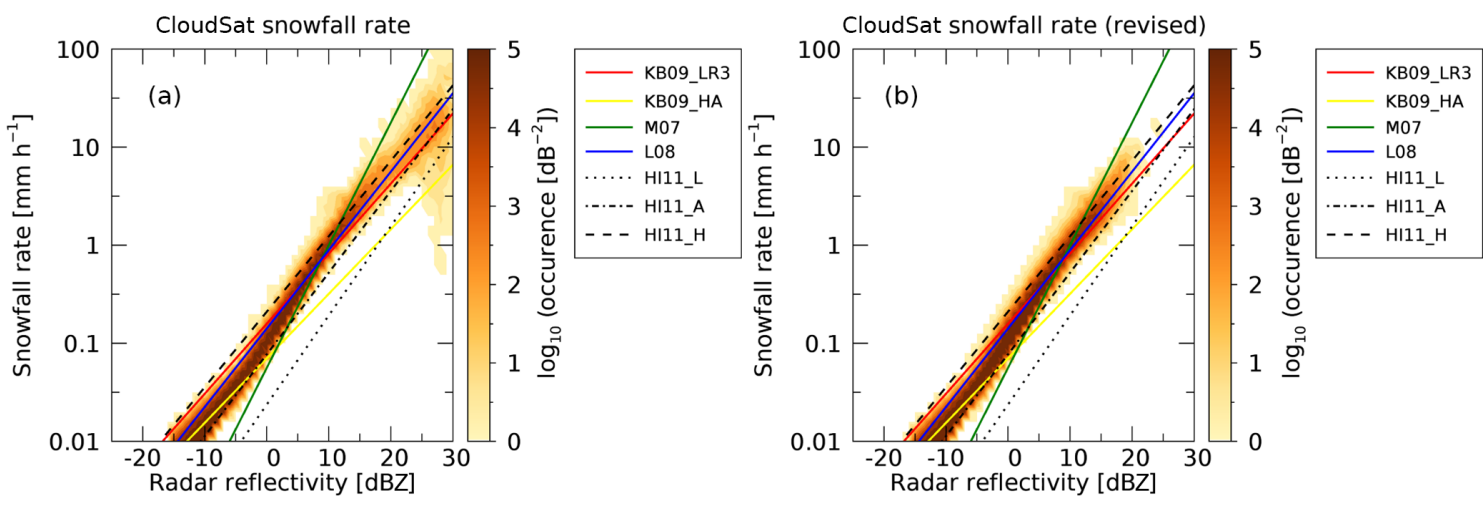

Figure 4. Histogram of occurrence of snowfall rate versus radar reflectivity for the entire CloudSat dataset over Greenland. Panel (a) shows the relation if the SNOWPROF surface snowfall rate is used as provided in the original SNOWPROF product. Panel (b) shows the relation with corrected topography. Different $Z-S$ relations are shown as well.

atmosphere to account for the higher topography estimates from BedMachine.

Comparing the panels in Fig. 4, we note that there is a significant number of high reflectivities associated with very high and often physically implausible snowfall rates of up to $50 \mathrm{~mm} \mathrm{~h}^{-1}$ (see upper right part of Fig. 4a). Using the BedMachine topography to update the estimated surface eliminates these high snowfall rates (see Fig. 4b). A visual inspection of a few of these cases indicates these are clutter-affected observations in the original CloudSat product, which are successfully eliminated using the BedMachine topography. The revised formulation for the lowest valid CloudSat bin above the surface thus leads to a significant reduction of surface clutter as shown in Fig. 4.

The impact of the above revisions can be seen in Fig. 5, which shows the actual heights of CloudSat surface snowfall rate observations above the surface, as well as the difference between the original SNOWPROF heights and the revised heights. It can be seen that in the original formulation the distance to the surface near the coast is often in the $1000 \mathrm{~m}$ range, which would likely lead to ground clutter (Maahn et al., 2014), in particular given the complex orography. Note that Fig. 5 shows the effect of the correction on the height of the lowest valid CloudSat observation above the surface (whereas Fig. 3 only shows the difference between two topographies). The impact of these differences in topographies (see Fig. 3) is amplified as CloudSat observations are binned at $240 \mathrm{~m}$ vertical resolution. Because of this $240 \mathrm{~m}$ binning, the slight changes in height observed in Fig. 3 can result in larger changes in CloudSat observation height as indicated in Fig. 5 (e.g., a difference in topography of $50 \mathrm{~m}$ might lead to the lowest valid CloudSat bin increasing by $240 \mathrm{~m}$ ).

Over the central GrIS the average observation height is not affected. We have examined this for the $1^{\circ} \times 2^{\circ}$ grid 

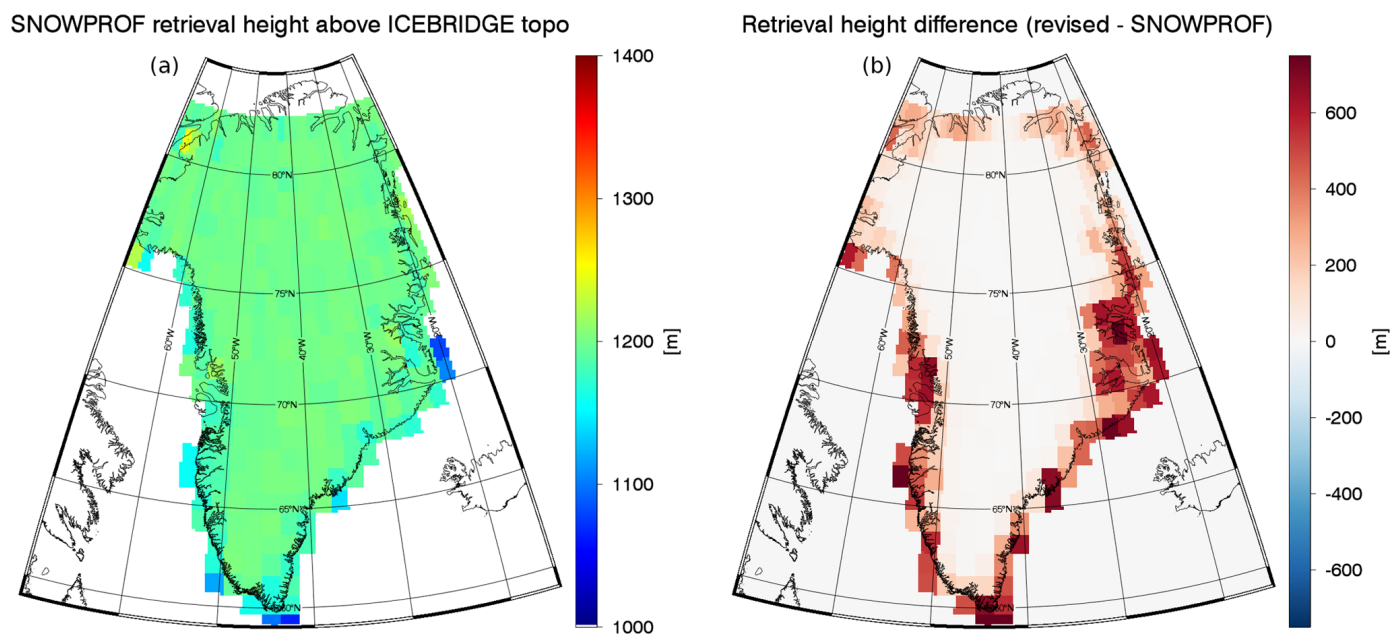

Figure 5. Panel (a) shows the height of the CloudSat SNOWPROF surface snowfall rate observation above the local topography (from IceBridge BedMachine). Panel (b) shows the difference between the height used in the revised product and original height. For example, at the southern tip of Greenland, the surface snowfall rate reported in the SNOWPROF product comes from an actual altitude of about $1000 \mathrm{~m}$ above the surface. In the revised formulation discussed in the text, this height is pushed up by 500 to $1500 \mathrm{~m}$.

box around Summit Station, where typically the fifth radar bin above the surface is selected (around $1200 \mathrm{~m}$ above the surface). In general, it is important to bear in mind that the CloudSat surface snowfall rate observations over structured terrain typically come from about $1200 \mathrm{~m}$ above the surface and thus do not observe precipitation processes below that altitude. The impact of CloudSat's "blind zone", where measurements are affected by ground clutter, below roughly $1200 \mathrm{~m}$ above ground for the high GrIS is studied in Sect. 3.2.

Figure 6 shows the integrated effect of the ground-clutter artifacts in the CloudSat surface snowfall rates on accumulation. The mean snowfall rate for all CloudSat data over Greenland would be approximately $0.225 \mathrm{~mm} \mathrm{~h}^{-1}$ in the revised formulation. Not correcting for artifacts reduces the mean by $15 \%$ to about $0.2 \mathrm{~mm} \mathrm{~h}^{-1}$, but with significant contributions from reflectivities larger than $20 \mathrm{dBZ}$, which are eliminated when the IceBridge BedMachine surface topography is applied. Observations that are corrected for ground clutter contribute toward the total snowfall at lower reflectivities, thereby increasing retrieved snowfall rates between +5 and $+15 \mathrm{dBZ}$ and increasing snowfall rate in this $\mathrm{dBZ}$ interval. Note that Fig. 6 only presents the grand mean of all snowfall rates. Because of the large differences in surface elevation between CloudSat and BedMachine near the coasts, the impact of artifacts in coastal areas will be much higher when snowfall climatologies are reported. In contrast, these artifacts will not play a major role in the higher elevations of the GrIS.

Based on the results reported in the current section, we will hereafter only use the revised snowfall rates that are obtained using the IceBridge BedMachine surface elevation and discard the surface snowfall rates reported in the SNOWPROF product. We again note that the revised surface snow-

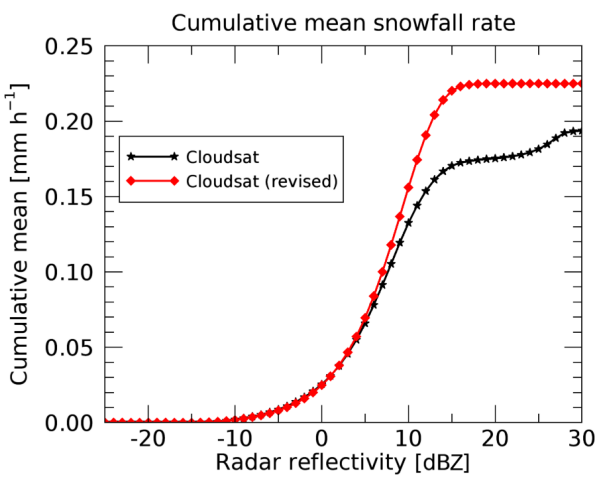

Figure 6. Impact of surface topography issues on cumulative snowfall rates.

fall rates we use here are also available in the SNOWPROF product. However, occasionally, mostly near the coasts, our analysis uses snowfall data from higher radar bins than the SNOWPROF surface snowfall rates to avoid clutter artifacts that would otherwise be present. We note that, while our paper was under review as a discussion paper, the issue of ground clutter was also studied independently by Palerme et al. (2019). Their findings corroborate the results we present here.

\subsection{Impact of height of observations above ground on estimated surface snowfall rate}

As shown in Fig. 5, CloudSat snowfall observations over Greenland stem from altitudes of around $1200 \mathrm{~m}$ above the surface to avoid ground clutter issues. This might cause several issues because any precipitation processes happening at lower altitudes are not observed and, consequently, not 

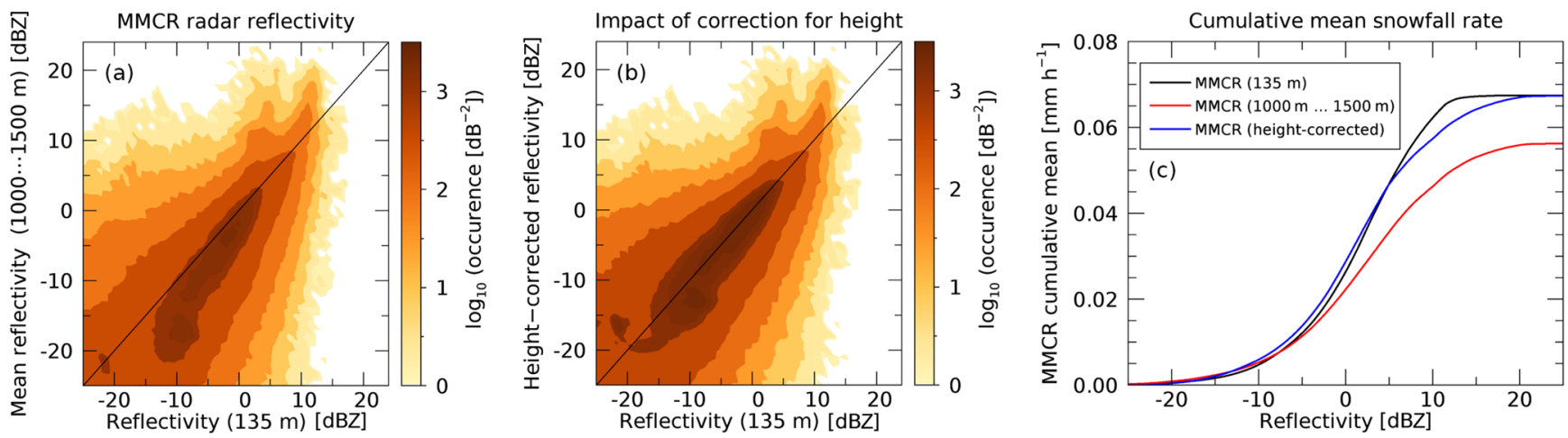

Figure 7. Panels (a) and (b) show histograms of MMCR observations at Summit. Panel (a) compares radar reflectivity at $135 \mathrm{~m}$ above the surface with the average radar reflectivity between 1000 and $1500 \mathrm{~m}$ above the surface, which corresponds to the height range where CloudSat observations are obtained. Panel (b) shows a similar plot but with a height correction applied. See text for details. Panel (c) shows cumulative mean snowfall rates for the different radar reflectivities show in (a) and (b).

accounted for in CloudSat estimates. Here we use MMCR observations from Summit to study the difference between the observed reflectivities at an altitude of $1200 \mathrm{~m}$ and those closer to the surface $(135 \mathrm{~m})$. We first average the vertical reflectivity profile of the MMCR between 1000 and $1500 \mathrm{~m}$ to account for the vertical resolution of CloudSat. After converting the averaged reflectivity back into units of decibel relative to $Z$ (dBZ), we compare it with the MMCR reflectivity observed at $135 \mathrm{~m}$ above the surface. This comparison is shown in Fig. 7a. One can see that for most cases, the MMCR reflectivity observed at CloudSat height (1000$1500 \mathrm{~m}$ ) is lower than the reflectivity near the surface, possibly owed to precipitation processes occurring at altitudes below $1000 \mathrm{~m}$. There are also cases where the upper reflectivity is higher than the reflectivity near the surface. Cases for such events could include non-precipitating clouds around $1200 \mathrm{~m}$ or ice particles sublimating before they reach the surface (virga). These cases might also include situations where the lowest MMCR radar bin saturates under high reflectivities (see Castellani et al., 2015). Our analysis of this saturation effect shows that $0.3 \%$ of the MMCR observations are impacted, with only a vanishing effect on the MMCR snowfall rates reported here. The correction developed in the following paragraph is also not affected. We therefore ignore this saturation effect.

By applying the KB09_LR3 $Z-S$ relationship (see Table 1), the red and black curves in Fig. 7c show the impact of the differences in reflectivity on total cumulative snowfall at Summit. The lower reflectivity at $1000-1500 \mathrm{~m}$ yields an underestimation of snowfall rate of about $20 \%$ compared to using the reflectivity near the surface. Most of this difference accumulated in a reflectivity range between -10 and $+5 \mathrm{dBZ}$.

In order to correct for this effect, we applied an ad hoc correction that statistically accounts for this effect:

$$
\begin{aligned}
& \mathrm{dBZ}_{\text {corrected }}= \\
& \quad \mathrm{dBZ}_{1000 \ldots 1500}+\left[\left(1-0.2 \times \mathrm{dBZ}_{1000 \ldots 1500}\right)>0\right] .
\end{aligned}
$$

This statistical correction produces the joint histogram shown in Fig. $7 \mathrm{~b}$ and, by design, matches the total cumulative snowfall near the surface (see blue curve in Fig. 7c). The correction was developed by fitting a regression line to the data between -20 and $+5 \mathrm{dBZ}$. The correction drops to zero at $5 \mathrm{dBZ}$ and thus does not affect reflectivities higher than $5 \mathrm{dBZ}$. While the above formula provides larger corrections to the very low reflectivity values, those corrections affect snowfall accumulation only very weakly. For example, for an observed reflectivity of $-30 \mathrm{dBZ}$, the correction is $+7 \mathrm{~dB}$, leading to a corrected reflectivity of $-23 \mathrm{dBZ}$, which does not produce any significant snowfall.

There are caveats to this correction: importantly, it will only work if the observed atmospheric states are statistically similar to the ones on which the correction was derived. Since the data used for the correction stems from Summit, we expect this correction not to produce viable results outside the high elevations of the GrIS. In order to highlight this limitation, we show in Fig. 8 the same analysis but for Barrow, Alaska. As one can see, the application of the correction outlined in Eq. (1) has no effect on the snowfall rate. This is because at Barrow snowfall is produced under different atmospheric conditions. The application of the correction also does not deteriorate the results at Barrow because it has, by design, little to no effect on higher reflectivities. This point is important as near the GrIS ablation zone and in Greenland's coastal regions one may expect atmospheric conditions to be more similar to Barrow than to Summit.

Results presented in Figs. 7 and 8 apply to the MMCR, which operates at Ka band. However, we wish to apply this relationship to CloudSat, which is a W-band radar. $Z-S$ relationships between Ka band and $\mathrm{W}$ band are different, because 

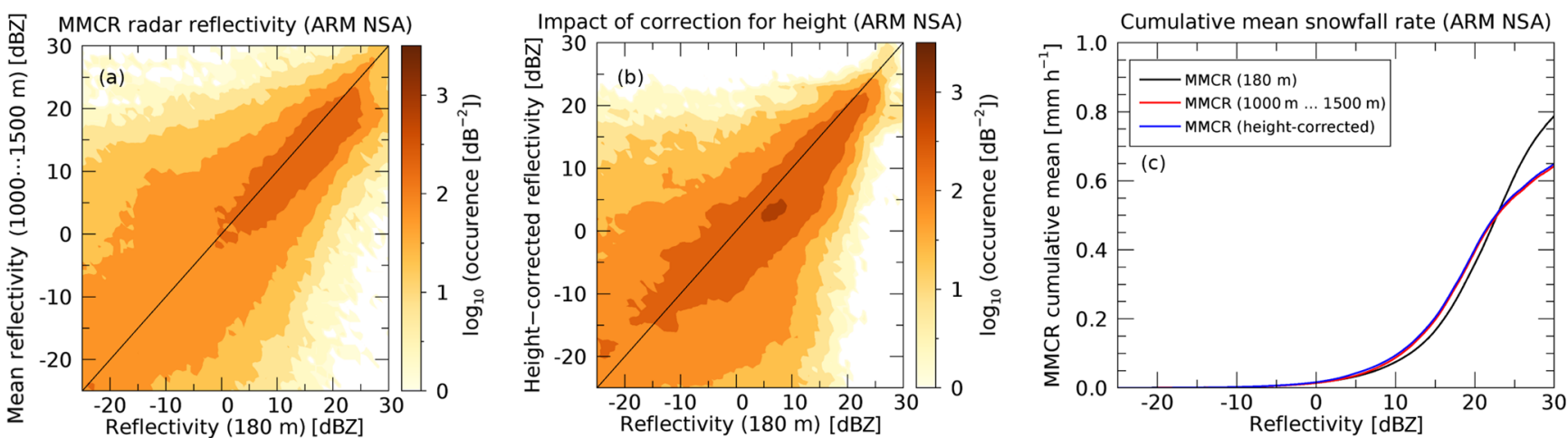

Figure 8. Same as Fig. 7 but for the DOE ARM site at the North Slope of Alaska (NSA) at Barrow, Alaska. The figures are based on 1.08 million radar profiles obtained between November 2008 and April 2011. Only data for the winter months of November through April are shown. The Barrow MMCR data were obtained from https://www.archive.arm.gov/discovery/ (last access: 9 June 2019 ).

medium-sized ice particles enter the Mie-scattering region at a smaller size at $\mathrm{W}$ band than at Ka band. As snowfall rate increases, the difference between $\mathrm{W}$ band and Ka band typically increases because the number of large particles outside the Rayleigh scattering region will increase at $\mathrm{W}$ band. This leads to a different slope of the $Z-S$ relationships at $\mathrm{W}$ band and $\mathrm{Ka}$ band, which might affect the correction proposed here. The $Z-S$ relationships for the two bands are shown in Fig. 9 for KB09_LR3. For other $Z-S$ relationships, depending on the ice particles used and, in particular, the underlying size distribution, these differences can be much larger. However, as discussed below, KB09_LR3 is likely more representative of the light snowfall observed over the high GrIS than other $Z-S$ relationships, which apply more to the midlatitudes. From Fig. 9, one can identify the slight difference in slope between Ka band and $\mathrm{W}$ band. However, since the above-proposed correction only has a significant effect in the range between -10 and $+5 \mathrm{dBZ}$, the impact of the earlier onset of Mie scattering in $\mathrm{W}$ band versus Ka band will be very small.

Based on this discussion, we will apply the aboveformulated correction to CloudSat observations without further modification for radar wavelength. This will affect the retrieved snowfall estimates over the higher elevations of the GrIS but will have little impact on estimates in the ablation zones near the coast, where snowfall is expected to be associated with higher reflectivities. In future studies it would be interesting to look at this issue further and study, for example, potential temperature dependencies. Initial results from Summit do show a weak dependency of the correction on surface temperature (not shown). We have also tested for a dependency on precipitation type using the classification by Pettersen et al. (2018) but did not find any significant differences in the correction between their IC (ice-only cloud) and LWC (liquid-water containing) clouds. However, expanding this analysis to more Arctic sites, such as Barrow, might allow for a more general correction that would help mitigate

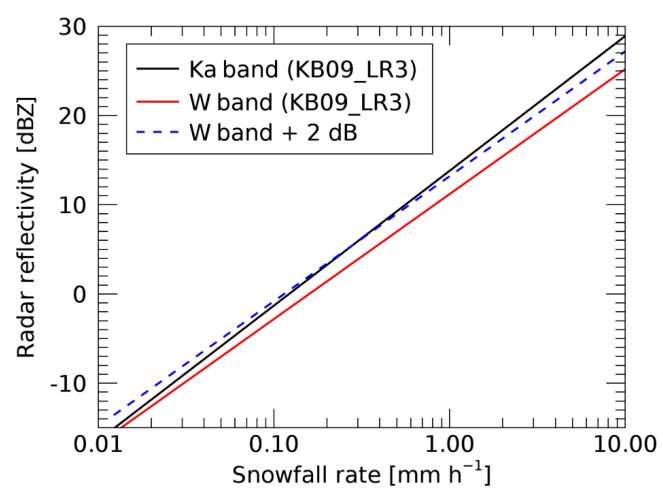

Figure 9. Radar reflectivity at Ka band (MMCR) and $\mathrm{W}$ band (CloudSat) as function of snowfall rate for KB09_LR3 Z-S relation. The dashed blue curve has the same slope as the red curve and is provided only as a visual reference to show the slight difference in slope between the red and black curves.

some of the issues related to the height above surface of CloudSat snowfall estimates.

A similar correction method has recently been developed by Souverijns et al. (2018). In contrast to our correction, their method works on retrieved snowfall rates rather than reflectivities. Their method is not directly applicable to our approach because we use a set of $Z-S$ relationships to determine uncertainty (see Sect. 2.4). Thus, a correction based on snowfall rate (rather than reflectivity) would be dependent on which $Z-S$ relationship is used. In general, we prefer performing such corrections on observations (radar reflectivity) rather than retrieved quantities (snowfall rate).

\subsection{Impact of $Z-S$ relation}

Figure 10 shows cumulative snowfall rates based on the full CloudSat dataset in a similar manner to Fig. 6. The original CloudSat SNOWPROF optimal estimation retrieval and L08, KB09_LR3, and M07 are relatively similar in their results (to 

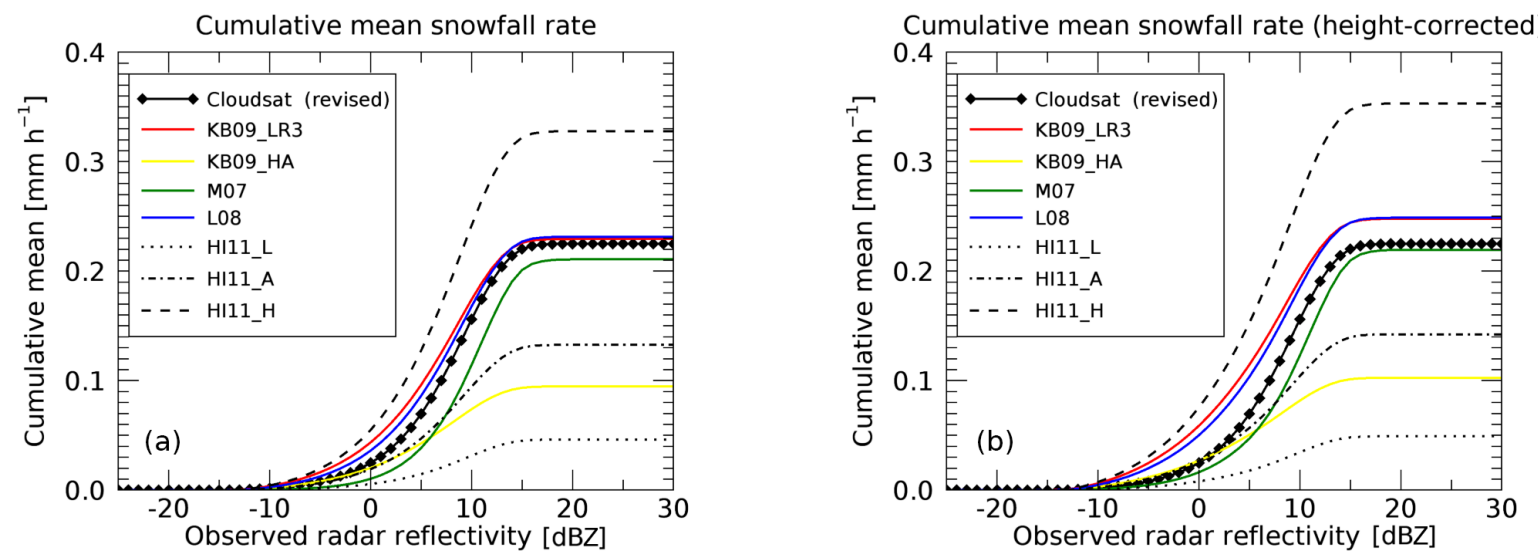

Figure 10. Cumulative snowfall rates derived from all CloudSat observations over Greenland. The thick black line corresponds to the CloudSat-derived surface snowfall rate from SNOWPROF with ground clutter removed (revised, same as in Fig. 6). The other lines correspond to the $Z-S$ relations applied to CloudSat reflectivities without height correction (a) and with height correction (b).

within $\pm 10 \%)$. All other $Z-S$ relationships fall outside that range. Figure $10 \mathrm{~b}$ shows the impact of the height correction (previous section) on the retrieval, which, by example of the KB09_LR3 relationship, increases cumulative snowfall rate near $30 \%$ at around $0 \mathrm{dBZ}$ and $7 \%$ at around $30 \mathrm{dBZ}$ (difference between red curves between Fig. 10a and b). Note that for the original SNOWPROF CloudSat retrieval this correction cannot be applied, as the original retrieval is an optimal estimation retrieval that cannot simply be recalculated with revised reflectivities.

Figure 10 also highlights the importance of low detectability thresholds for space-borne precipitation radar if GrIS snowfall is to be observed. About $50 \%$ of the total accumulation over the GrIS occurs at reflectivities between $-10 \mathrm{dBZ}$ and $+7 \mathrm{dBZ}$. A minimum radar detectability threshold should therefore be lower than $-10 \mathrm{dBZ}$ to accurately account for snowfall over the GrIS.

\subsection{Comparison of Summit Station snowfall estimates against snow stake field}

Snow stake field accumulation measurements are available from 2007 onwards and coincide with CloudSat data availability, as well as with the availability of MMCR observations from ICECAPS. Here we compare both radars to the stake field observations.

\subsubsection{MMCR versus stake field}

In Fig. 11, we compare liquid equivalent snowfall accumulation derived from MMCR and POSS with the geometric accumulation obtained from the stake field. The ratio between the two quantities is the effective density the snowpack would need to have to account for the accumulation via the radar-derived liquid equivalent snowfall rates. As mentioned earlier, the snow stake field is read typically once per week. In order to obtain corresponding MMCR (or POSS) accumu- lation for each snow stake field observation period (week), we added up all MMCR (or POSS) snowfall rates for that same period. For the MMCR we used three different $Z-S$ relationships. The POSS reports snowfall rate based on Sheppard and Joe (2008), so only this one value was obtained. Figure 11 shows the derived liquid equivalent snowfall rate from MMCR (or POSS) plotted against the stake field accumulation. The ratio between the stake field accumulation and the MMCR (or POSS) accumulation can be interpreted as the effective density that would be needed to explain the observed stake field snowfall accumulation by the liquid equivalent snowfall of the MMCR or POSS (see also Castellani et al., 2015).

One can see that between the different $Z-S$ relationships used most yield an effective snowpack density around $100 \mathrm{~kg} \mathrm{~m}^{-3}$. Only KB09_LR3 yields a significantly higher effective density of $426 \mathrm{~kg} \mathrm{~m}^{-3}$. As discussed in Sect. 2.5, observed densities in the upper snow layers at Summit are likely in the range of $240-380 \mathrm{~kg} \mathrm{~m}^{-2}$. None of the above $Z-S$ relationships fall into that range. Based on this consideration and the slightly higher correlation between stake field and radar estimates, KB09_LR3 is likely closest to a representative $Z-S$ relationship for Summit, although it likely overestimates actual accumulation slightly. KB09_LR3 would also be most consistent with the type of snowfall often observed at Summit, that is, mostly individual ice crystals with little aggregation or riming (e.g., Pettersen et al., 2018). Deposition onto (or sublimation from) the snow surface is not accounted for in these estimates. If deposition (sublimation) was included it would somewhat enhance (reduce) the accumulation observed by the radar. Based on ERA-Interim reanalysis data, the effect of sublimation/deposition is very small $(\sim 2 \%)$. 

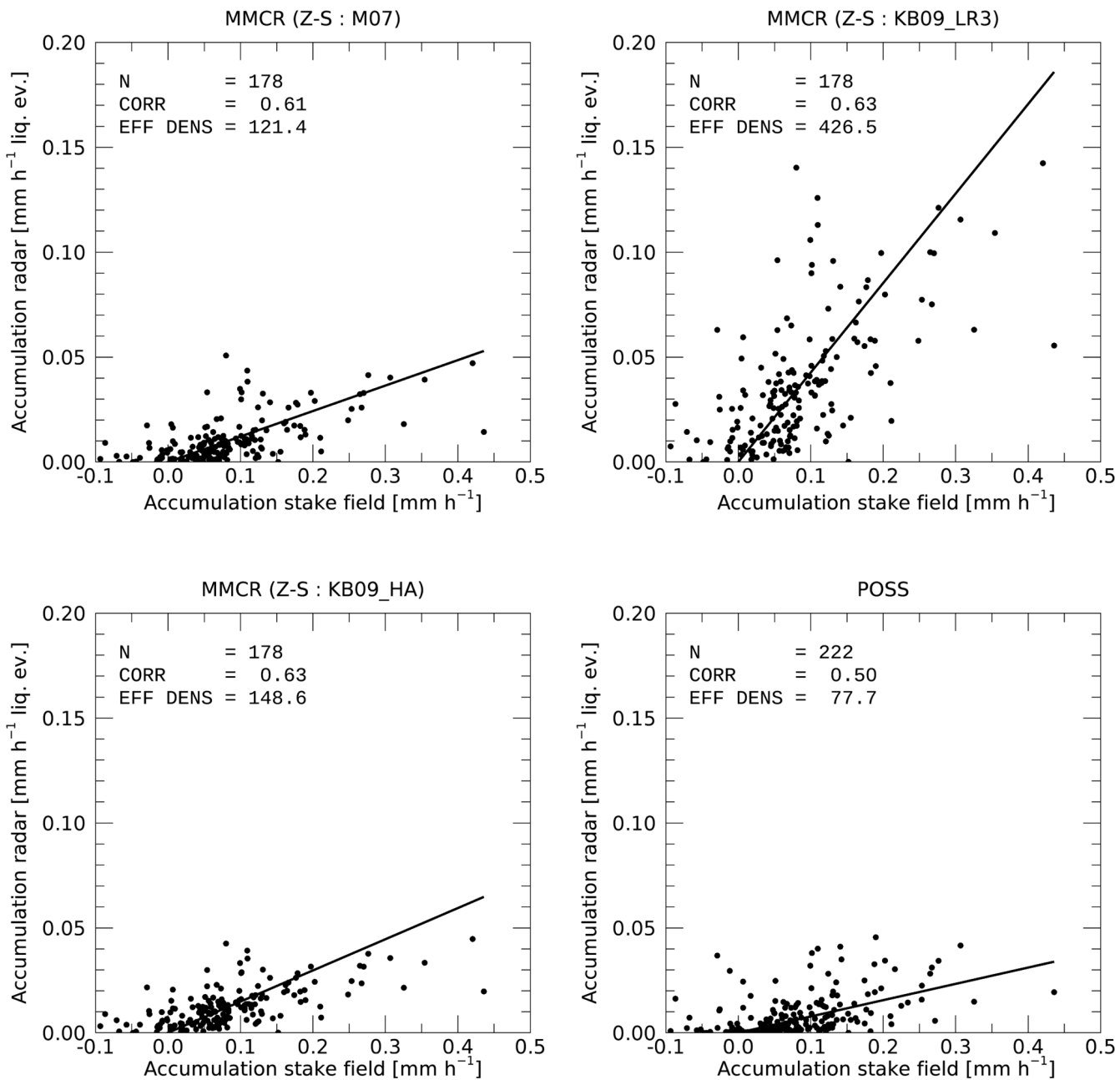

Figure 11. Comparison between snowpack accumulation rates from stake field and MMCR-derived or POSS-derived liquid equivalent accumulation rates. EFF DENS is the effective density in kilograms per cubic meter $\left(\mathrm{kg} \mathrm{m}^{-3}\right)$ of the snowpack needed to explain the mean stake accumulation by the liquid equivalent precipitation from either MMCR or POSS. The lines start at $[0,0]$ and have the reported effective density (divided by 1000) as slope. Each data point corresponds to 1 week of observations as the snow stake heights are read typically once a week.

\subsubsection{CloudSat versus stake field}

To compare CloudSat observations with the snow stake field, we selected all CloudSat data (height- and clutter-corrected) within $50 \mathrm{~km}$ from Summit and averaged them over the time intervals between stake field observations, which are typically in weekly intervals. We rejected any matchups where there were less than 30 CloudSat observations within a given snow stake field time interval. This resulted in 369 pairs of weekly accumulation statistics from CloudSat and concurrent snow stake field observations over the time period 2007 2016.

Figure 12 shows the accumulation rates obtained from CloudSat compared to the snow stake field for 369 data points for different $Z-S$ relationships. Compared to the corresponding figure for MMCR (previous section), correlations are much lower. This increased scatter is not surprising as
CloudSat provides only one to three orbits per week around Summit. However, in terms of total accumulation over longer time periods, CloudSat does show a good agreement with the snow stake field as shown in Fig. 13. We note that the good agreement of the total accumulation seen in Fig. 13 is by design, as the effective density is used to scale the CloudSat observations to the snow stake field. However, the curves follow each other closely over the entire observation period, which could not necessarily be expected if, for example, CloudSat would preferably sample certain types of snowfall. The good agreement in accumulation is despite the large scatter between CloudSat and the stake field seen in Fig. 12. This scatter can partly be explained by CloudSat not being perfectly collocated in space and time with the ground-based observations, as well as by relatively few individual CloudSat overpasses contributing to each weekly average. Often CloudSat 

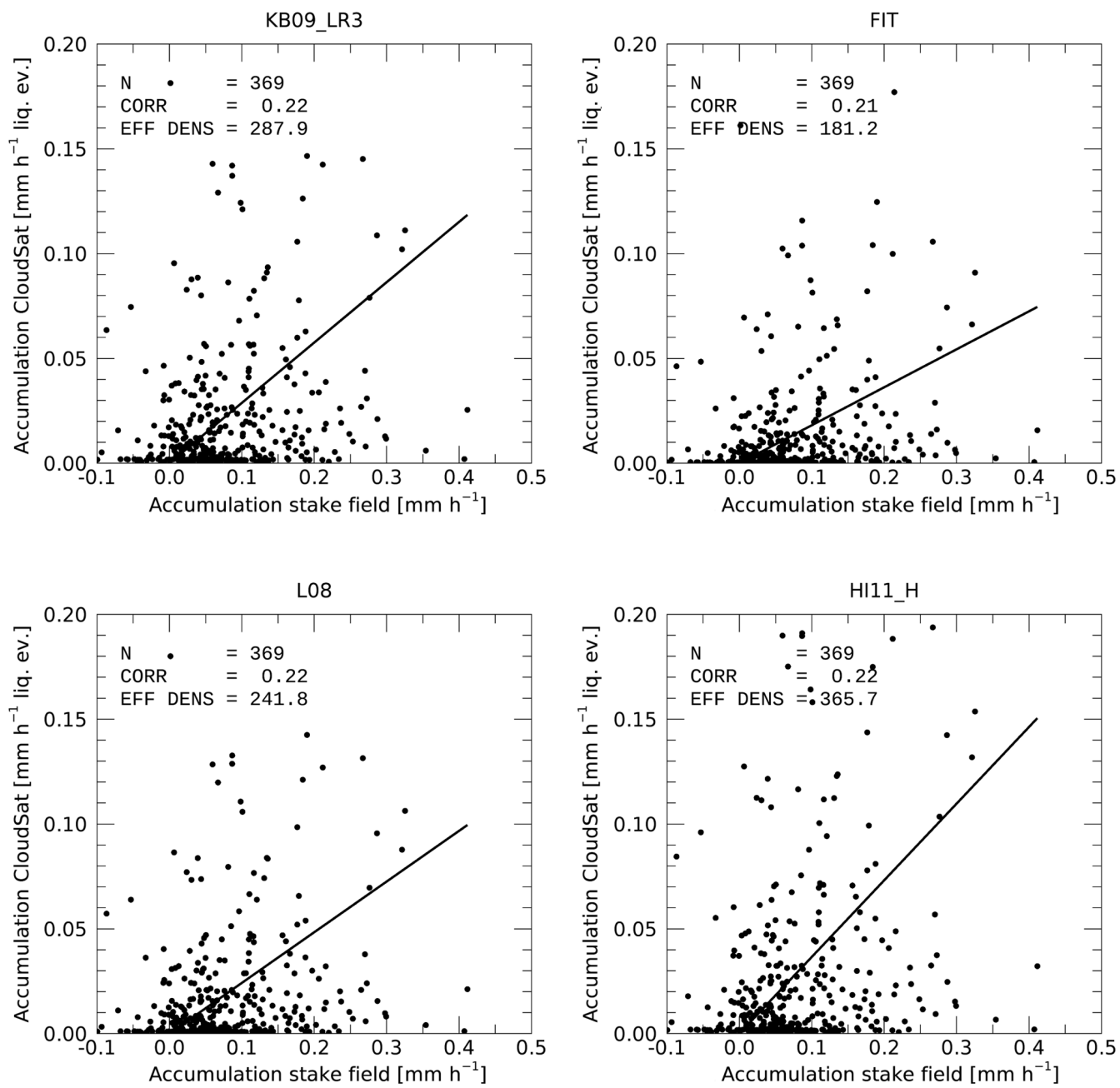

Figure 12. Same as Fig. 11 but for CloudSat versus stake field.

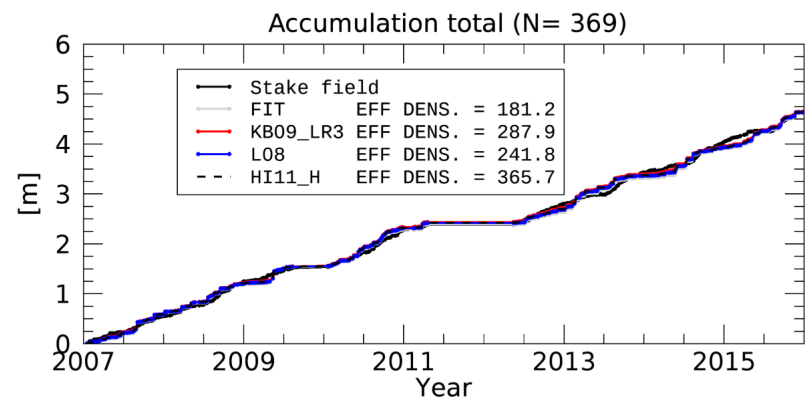

Figure 13. Total snowfall from CloudSat and stake field for all 369 weeks where data were available for both CloudSat and the stake field.

might miss an individual snowfall event and hence report a near-zero snowfall rate. In other cases, CloudSat might observe a single snowfall event, which is not representative for the entire week, and thereby overestimate the weekly snowfall. Both effects can be observed in Fig. 12.

Similar to the above discussion on MMCR, choosing an appropriate $Z-S$ relationship remains critical in terms of the effective density needed to transfer CloudSat liquid equivalent snowfall rates to accumulation. The four $Z-S$ relationships shown in Fig. 12 provide effective density values between 181 and $365 \mathrm{~kg} \mathrm{~m}^{-3}$, providing a generally better agreement with the numbers of $240-380 \mathrm{~kg} \mathrm{~m}^{-2}$ discussed in Sect. 2.5. The three $Z-S$ relationships (HI11_H, KB09_LR3, and L08) produce a mean value of $298 \mathrm{~kg} \mathrm{~m}^{-2}$.

Figure 13 shows the accumulation at Summit between 2007 and 2016 based on 369 weeks where concurrent CloudSat observations were available and using the effective densities reported in Fig. 12 for the three different $Z-S$ relationships. Total accumulation based on these estimates is about $65 \mathrm{~cm} \mathrm{yr}^{-1}$, derived from the $4.75 \mathrm{~m}$ of accumulation seen in Fig. 13 over the 369 weeks.

Based on the findings presented here, we will from here on apply the three $Z-S$ relationships that produced realistic effective densities and average them to obtain a final surface snowfall estimate for each CloudSat observation. The spread 
between the three relationships is used to determine an uncertainty range.

\subsection{Final form of retrieval used}

Based on the findings in the previous sections, the final CloudSat processing used from here on consists of three steps.

1. We find the fifth radar bin above the IceBridge BedMachine topography and use this radar bin to derive snowfall rates as outlined in Sect. 3.1. This step results in a set of radar reflectivities observed by CloudSat typically at altitudes around $1200 \mathrm{~m}$ above the surface.

2. We correct the so-obtained reflectivities for the height difference between their observation height (around $1200 \mathrm{~m}$ ) and the surface following the method outlined in Sect. 3.2. This step results in a set of height-corrected reflectivities.

3. We then apply the three $Z-S$ relationships (HI11_H, KB09_LR3, and L08; see Sect. 3.3) to convert those reflectivities to equivalent snowfall rates. We average the three estimates to get a final surface snowfall estimate and use the spread between the three as an estimate for uncertainties related to the choice of $Z-S$ relationship. Throughout the entire process we use the official CloudSat SNOWPROF product solely to determine precipitation type. That is, only if the SNOWPROF product reports snowfall, we use the snowfall rate derived according to the approach outlined here. This screens out cases with high reflectivity that are associated with rainfall.

These derived snowfall rates will form the basis of all further discussion from here on.

\section{Comparison of CloudSat with ERA-Interim snowfall climatology}

Using the strategy laid out in the previous section, we derive monthly mean CloudSat estimates over the GrIS for all months where CloudSat data are available and at a resolution of $1^{\circ} \times 2^{\circ}$, which roughly corresponds to $111 \mathrm{~km} \times 111 \mathrm{~km}$ at $60^{\circ} \mathrm{N}$. In comparison, the resolution of ERA-Interim reanalysis at $60^{\circ} \mathrm{N}$ is $0.7^{\circ} \times 0.7^{\circ}$ or $78 \mathrm{~km} \times 39 \mathrm{~km}$. Figure 14 shows the annual mean values (calculated as a mean of monthly means) for CloudSat (Fig. 14a) and ERA (Fig. 14b), as well as their relative difference in percentage (Fig. 14c). Figure 15 shows the annual cycle over the GrIS.

Marked differences between ERA-Interim reanalysis and CloudSat exist in the months June-September, where ERA shows less precipitation over the GrIS than CloudSat. For the summer months, the spatial correlation between ERA and CloudSat is also worst. Differences are most pronounced over the high GrIS north of $72^{\circ} \mathrm{N}$, where ERA shows very little precipitation. These differences can also be identified in the monthly snowfall plots shown in Figs. 16 and 17. It is interesting to note that the area where the ERA-Interim reanalysis product seems to underestimate snowfall coincides nearly perfectly with areas where the CloudSat-derived snowfall is associated with low, cumuliform snowfall (see Fig. 10a in Kulie et al., 2016). The months with the highest positive bias (Fig. 15c) also show the lowest spatial correlation between ERA-Interim reanalysis data and CloudSat snowfall estimates (Fig. 15b).

Total snowfall over the GrIS from CloudSat adds up to $34 \pm 7.5 \mathrm{~cm} \mathrm{yr}^{-1}$ liquid equivalent, where the uncertainty range is given by the spread in $Z-S$ relationships. The ERA estimate is $30 \mathrm{~cm} \mathrm{yr}^{-1}$. Comparing these results to an earlier publication (see Table 1 in Cullather et al., 2014), we find our ERA-Interim reanalysis estimate to be lower. The various total snowfall values reported in Table 1 in Cullather et al. (2014) show a wide spread depending on which model was used. Further, the values in Cullather et al. (2014) refer to total precipitation, whereas our values are snowfall only. Ettema et al. (2009) find a fraction of $6 \%$ liquid and $94 \%$ snow over the GrIS, which can only partly explain the bias we see for ERA-Interim compared to Cullather et al. (2014). Snowfall rates from CloudSat are in better agreement with other studies. For example, Ettema et al. (2009) report snowfall over the GrIS based on high-resolution model simulations to be $40.7 \mathrm{~cm} \mathrm{yr}^{-1}$ ( $94 \%$ of their total precipitation), which is higher than both the CloudSat and ERA estimates reported here but still in agreement with CloudSat within the range of uncertainty of the CloudSat retrievals.

Figures 16 and 17 show the monthly mean spatial distribution of snowfall from CloudSat and ERA, respectively. Both datasets identify a band near the southwest coast of Greenland, where snowfall in summer is near zero. These coastal areas are presumably too warm in summer for snow to reach the ground before melting. Note that the CloudSat data are at a coarser $\left(1^{\circ} \times 2^{\circ}\right)$ resolution than the ERA-Interim reanalysis data, which explains this narrow coastal feature to be less pronounced in CloudSat compared to ERA.

\subsection{Snowfall by drainage system}

As can be seen in Fig. 14, even at a resolution $1^{\circ} \times 2^{\circ}$, the monthly CloudSat precipitation estimates over the GrIS are relatively noisy. As a nadir-looking instrument, CloudSat only provides few overpasses per grid-box per month. In addition to grid-box-averaged precipitation estimates, we therefore also evaluate CloudSat per major GrIS drainage system. We first binned CloudSat data onto the $0.7^{\circ} \times 0.7^{\circ}$ ERAInterim reanalysis grid and subsequently averaged these gridded data onto the drainage basins.

Figures 18 and 19 show the annual cycle of precipitation for the different major GrIS drainage areas as defined by Zwally et al. (2012). Consistent with earlier studies (Berdahl et al., 2018), the southeast of Greenland experiences the 

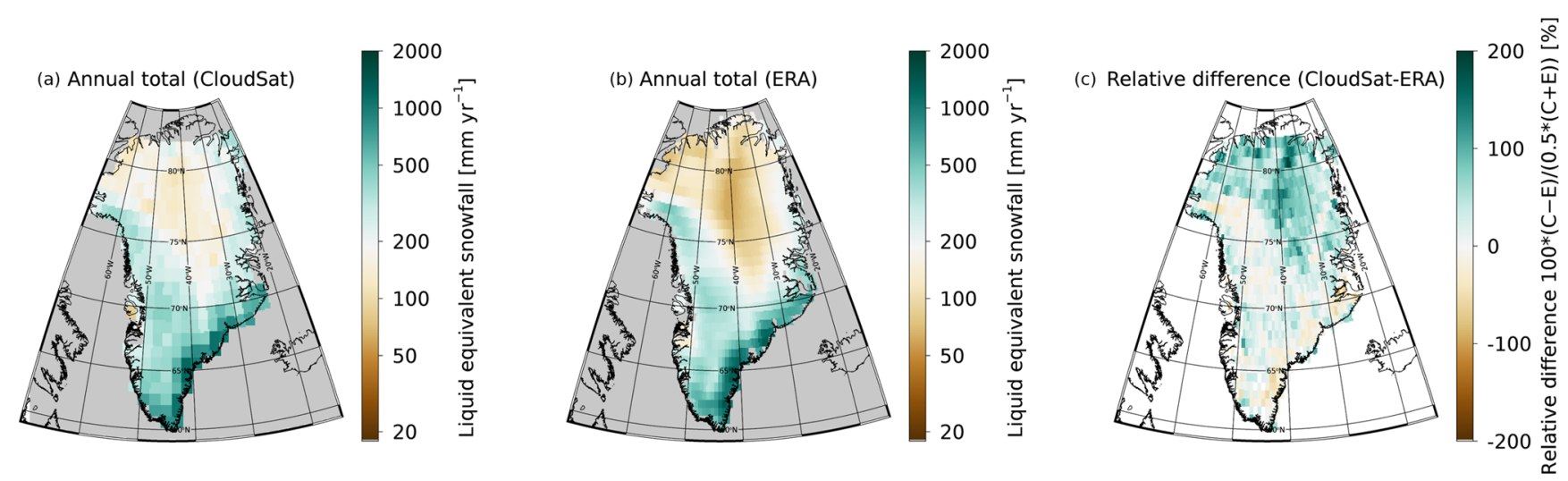

Figure 14. Annual mean liquid equivalent snowfall from CloudSat (a), ERA-Interim (2006-2016, b), and the relative difference between both (c).
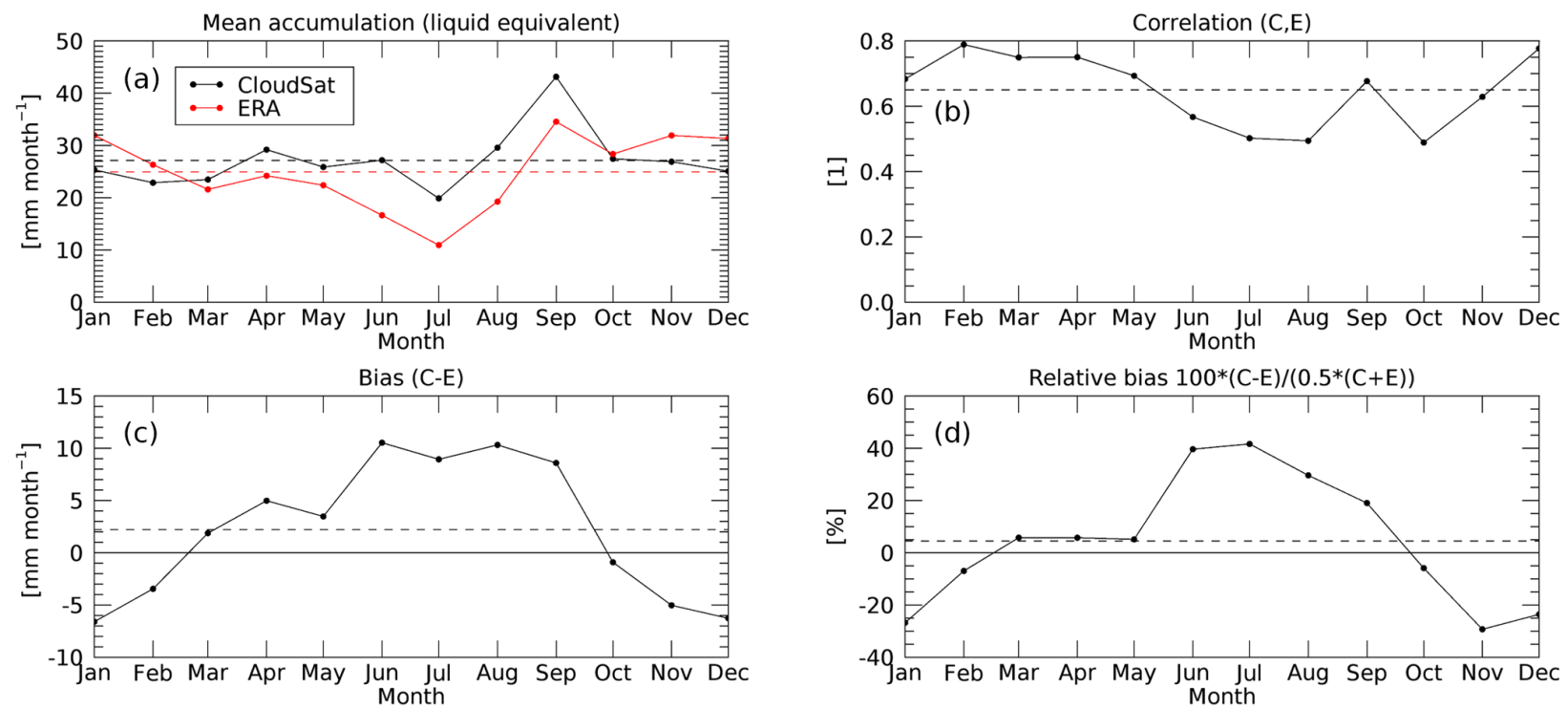

Figure 15. Annual cycle of liquid equivalent snowfall over the GrIS from CloudSat and ERA-Interim (a), spatial correlation between the two (b), mean bias (c), and mean relative bias (d). The dashed horizontal lines represent the annual average.

highest mean snowfall, and snowfall there peaks typically in wintertime. We note that the snowfall values reported in Berdahl et al. (2018) are much higher than our estimates but also higher than other published estimates (e.g., Cullather et al., 2014). This appears to be related to Berdahl et al. (2018)'s use of only coastal stations, which experience more precipitation than inland (Mira Berdahl, personal communication, 10 May 2018). In contrast, much of the northern parts of the GrIS receive very little snowfall, but peak snowfall in those areas is in August. These features can also be observed in Figs. 16 and 17.

Figure 19 compares the annual cycle of snowfall between CloudSat and ERA for all drainage areas. With few exceptions, the annual cycles between CloudSat and ERA are very similar. Furthermore, the summertime negative bias of ERA is apparent for many of the more northern drainage areas (e.g., Area 1.1). In some areas on the east coast of Greenland (e.g., Area 3.3), the agreement between CloudSat and ERA is strikingly good. The agreement in these areas seems to indicate that snowfall associated with cyclonic activity over the southeast of Greenland is represented well by ERA, whereas snowfall associated with summertime precipitation is potentially underrepresented in the reanalysis model.

The dashed curves in Fig. 19 are cosine fits of the annual cycle of precipitation, which are used to determine the months of maximum snowfall as well as the amplitude of snowfall reported in Fig. 18. We note that these cosine fits do not necessarily correspond to physical features in the annual cycle of precipitation for all drainage systems, so the values given for the annual cycle in Fig. 18 should not be interpreted too quantitatively. It does appear, however, that large parts of the central and northwestern GrIS see maximum precipita- 

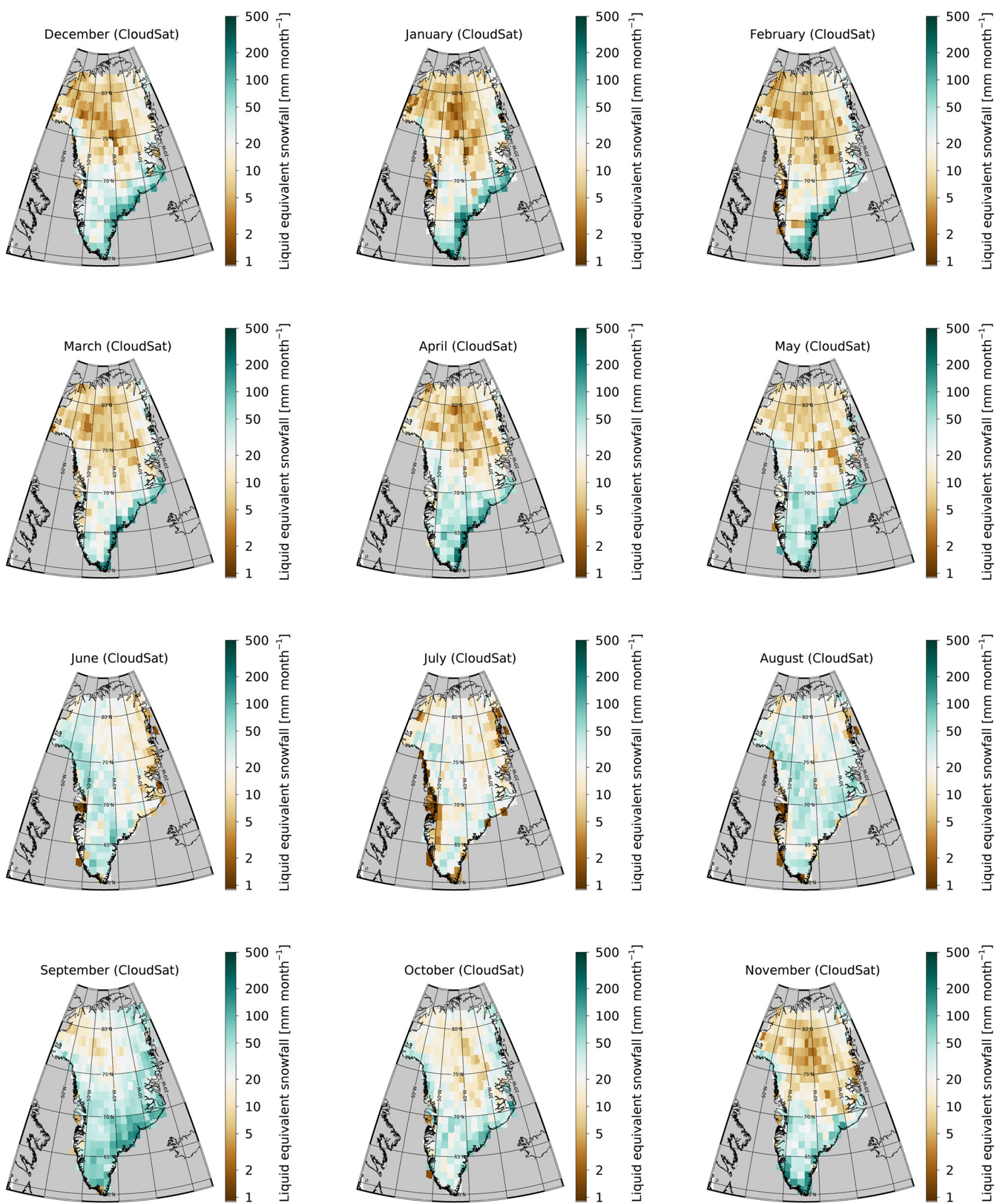

Figure 16. CloudSat-derived monthly mean snowfall rates. 

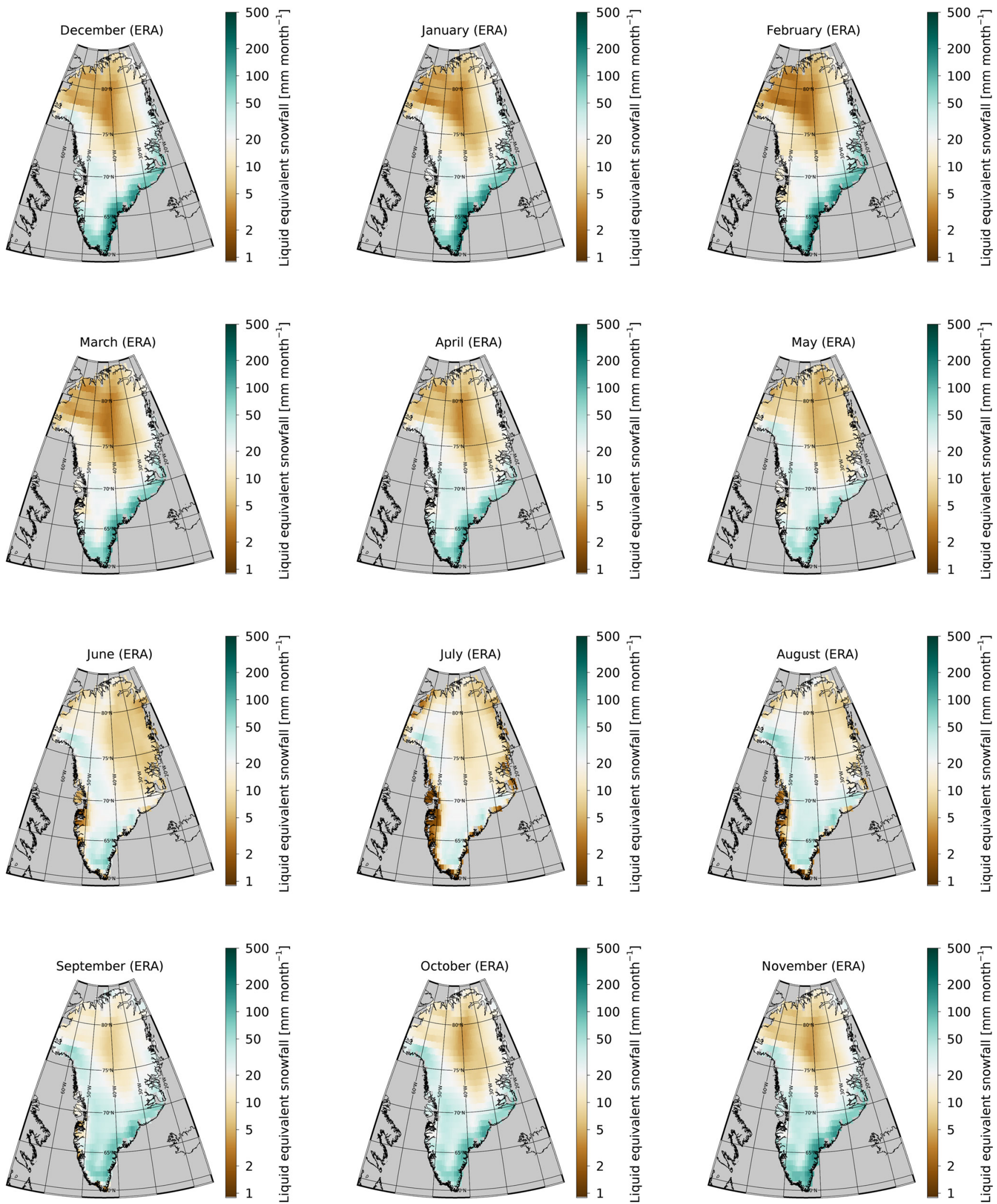

Figure 17. Same as Fig. 16 but for ERA-Interim. 


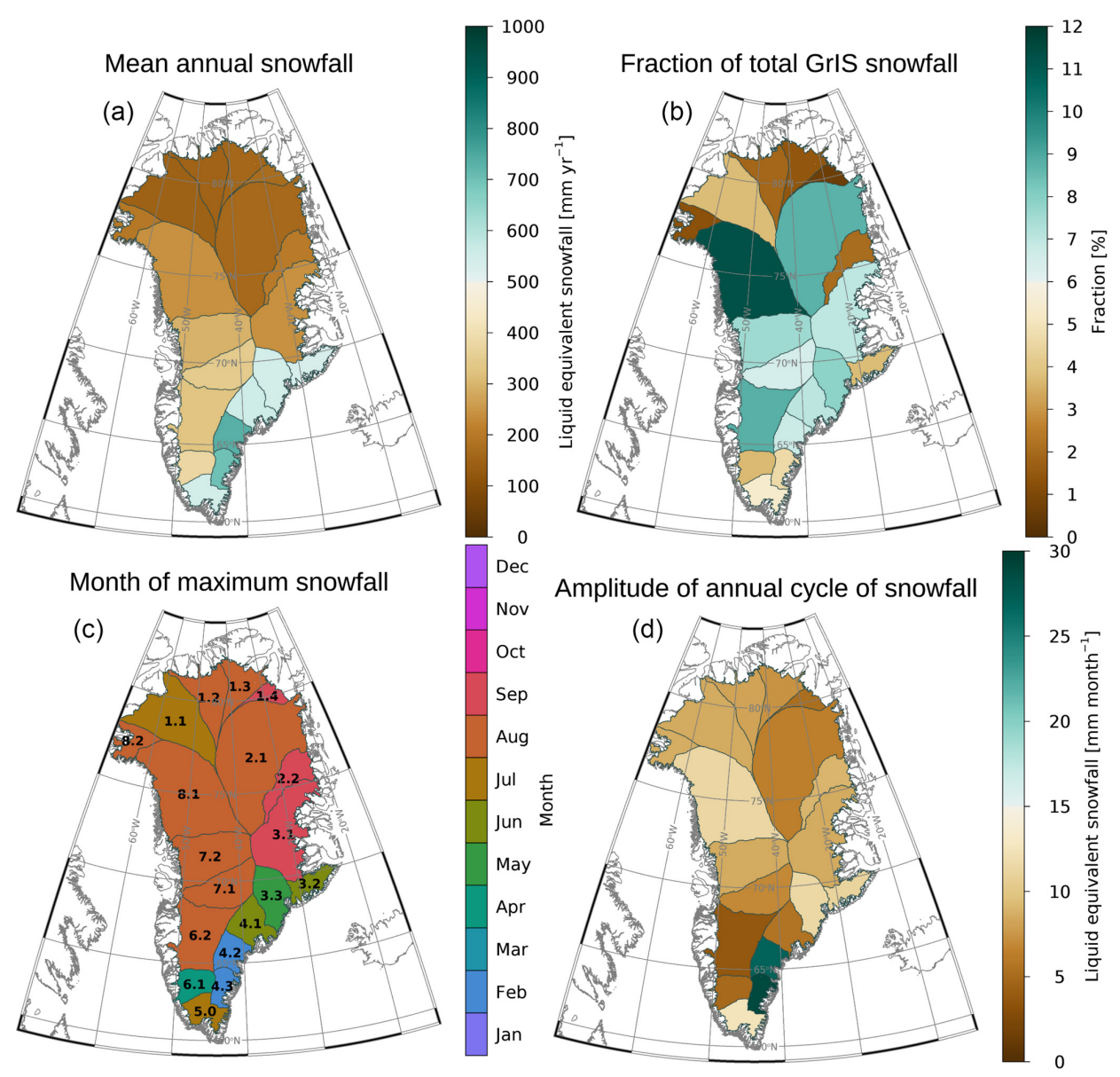

Figure 18. Annual snowfall associated with the different drainage systems defined by Zwally et al. (2012). Panel (a) shows the mean annual snowfall, panel (b) shows the fractional contribution to the total snowfall over the GrIS, panel (c) shows the month of maximum precipitation as well as the drainage-basin identifier used in Zwally et al. (2012), and panel (d) shows the amplitude of the annual cycle of snowfall. The month of maximum precipitation and amplitude are derived using a cosine fit to the annual cycle (see Fig. 19).

tion in summer, whereas the southeastern part of the GrIS sees maximum precipitation in winter.

In the next section we further investigate the differences between ERA-Interim reanalysis and CloudSat based on monthly mean snowfall accumulation over Summit, where independent observational data are available.

\subsection{Annual cycle of snowfall at Summit}

Figure 20 compares monthly mean snowfall rates over Summit from all data sources discussed here. The snow stake field data have been corrected for sublimation/deposition using ERA estimates and converted to liquid equivalent snowfall in order to make results directly comparable to the other snowfall estimates. Cullen et al. (2014) study sublimation/deposition over the high GrIS in detail and find the contribution of sublimation/deposition to be generally around $2 \%$ of the total accumulation. On a monthly basis, values from ERA were a bit higher but still did not significantly alter the snow stake field values. The CloudSat snowfall esti- mates agree well with the snow stake field with the exception of June and July, where CloudSat (as well as the MMCR) report much higher snowfall accumulation than the snow stake field. A similar discrepancy between June/July stake field observations and other snowfall measurements was already reported by Dibb and Fahnestock (2004). Castellani et al. (2015), in their Fig. 4, show a similar behavior. Notably, June and July are the months with the highest interannual variability in snowfall. For completeness, we have also included the annual cycle based on the original CloudSat SNOWPROF retrieval (green). One can see that using the SNOWPROF surface snowfall rate retrieval without the corrections discussed and applied here would yield a precipitation estimate lower than ERA and would also fail to show the strong annual cycle seen in the other observational datasets. 

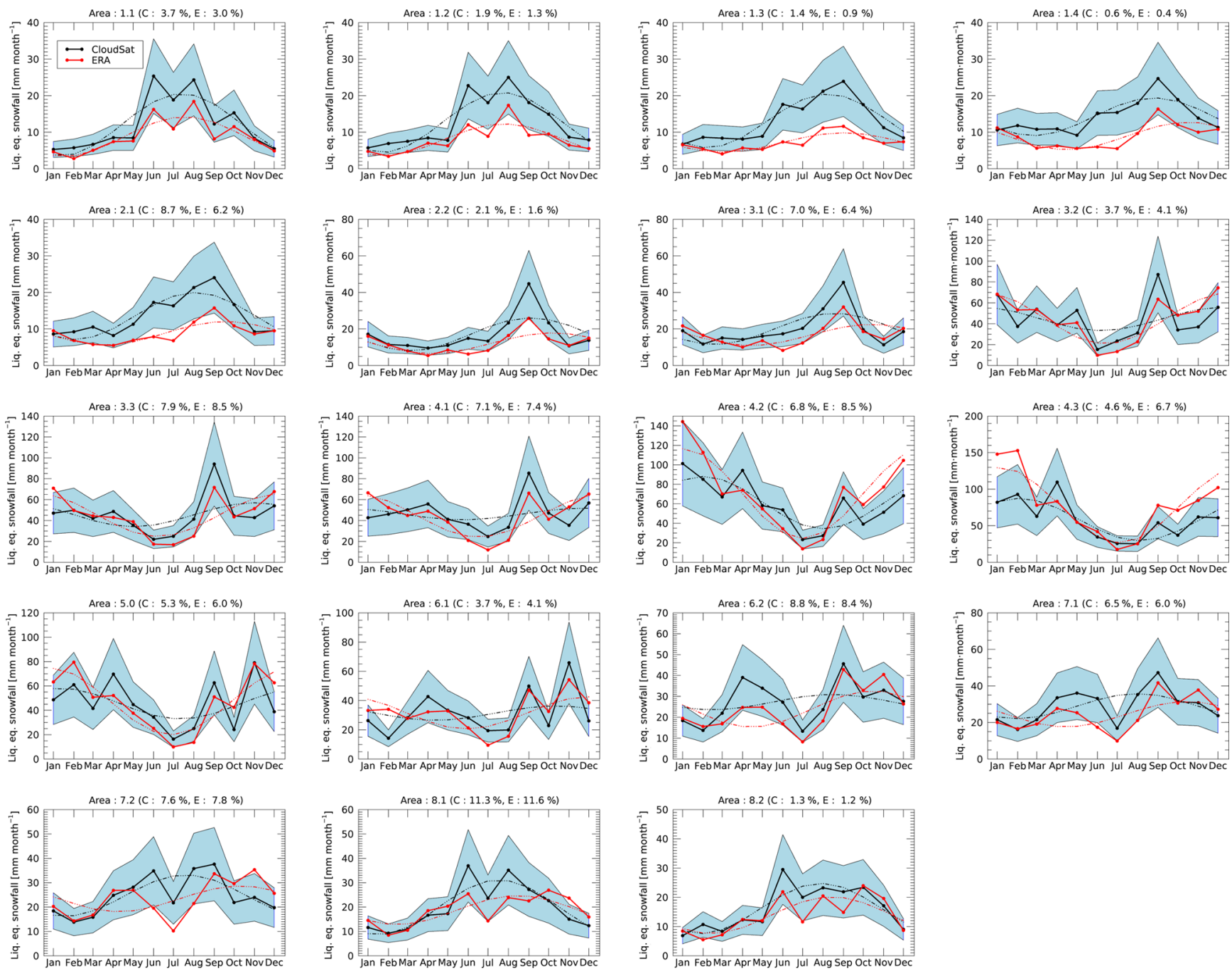

Figure 19. Annual cycle of precipitation for the different drainage systems shown in Fig. 18 for both CloudSat and ERA-Interim (20062016). The shaded area gives the uncertainty due to $Z-S$ relation. The dashed curves give a cosine fit to the annual cycle. The numbers in brackets in the total are the factional contribution of each drainage area to the total snowfall over the GrIS. Note the different scales of the $y$ axes.

\section{Conclusions}

Snowfall estimates from space-borne radars such as CloudSat provide estimates of snowfall in remote regions where networks of ground-based observations are difficult to establish. At the same time, these space-borne observations are difficult to validate, and potential systematic error sources related to ground clutter and the height of the space-borne observations over ground need to be addressed. Here we provided simple approaches to mitigate these adverse effects for the GrIS. We rely on auxiliary information, namely the IceBridge topography, to better characterize surface height, and the MMCR as a proxy for understanding the relationship between radar reflectivity at the observation height of CloudSat and near the surface. In particular, the correction for the observation height based on MMCR is strictly empirical and can certainly be improved upon for example by more explicitly accounting for physical processes, e.g., sublimation, between the height of observation and the surface. This issue is not unique to the GrIS but might affect CloudSat snowfall estimates in other parts of the world as well. Despite remaining uncertainties, our assessment of CloudSat-derived snowfall over the GrIS shows in general good agreement with more direct ground-based observations at Summit. Since CloudSat is a nadir-only radar, its sampling does not allow for a fine horizontal resolution, and even at a resolution of $1^{\circ} \times 2^{\circ}$ CloudSat estimates of annual mean snowfall show considerable noise. We have therefore sampled CloudSat snowfall estimates into larger areas that coincide with Greenland drainage basins. Comparing the annual cycle of CloudSat-based snowfall with ERA-Interim for these areas shows that the ERA- 


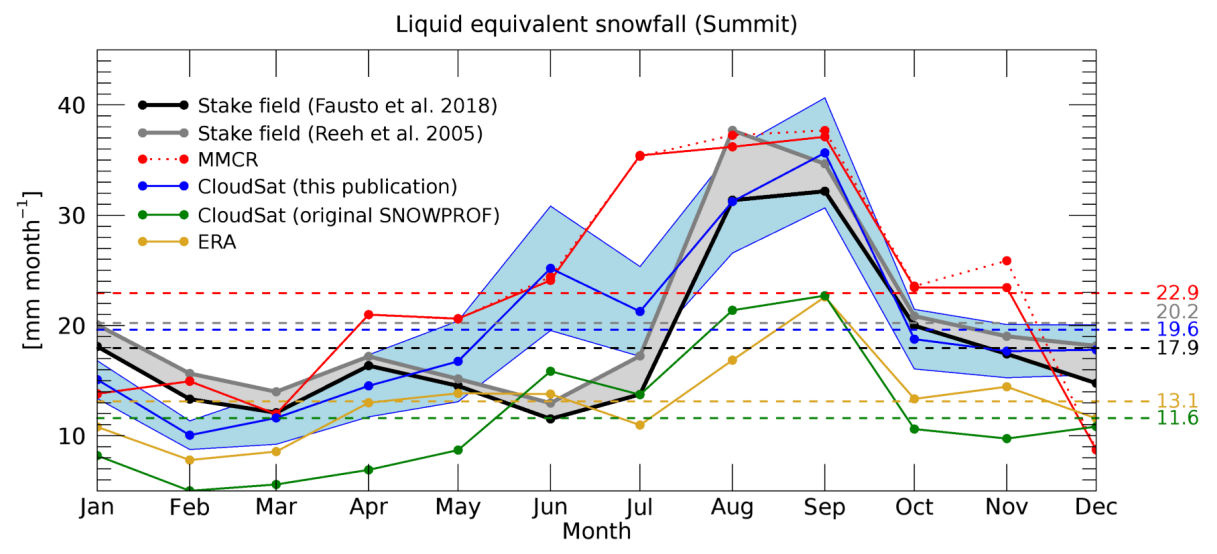

Figure 20. Liquid equivalent snowfall over Summit from different data sources used in this publication. The shaded uncertainty range around the CloudSat estimate gives the uncertainty due to $Z-S$ relation. The shaded uncertainty range around the stake field estimates gives the uncertainty due to different assumption about snow density. The stake field estimates presented herein have been corrected for sublimation/deposition using ERA-Interim sublimation/deposition estimates. For MMCR we used the KB09_LR3 Z-S relation (see Table 1).

Interim reanalysis generally produces robust results in areas where snowfall appears dominated by the large-scale precipitation systems. On top of the GrIS and in more northerly areas, ERA-Interim appears to miss some of the summertime precipitation that is related to shallow, more convective precipitation. This result might well be specific to ERA-Interim reanalysis, and in future studies it will be interesting to test different climate models and reanalyses against the CloudSat dataset. For example, Behrangi et al. (2016) examined the representation of high-latitude precipitation in different reanalysis products and found significant differences. Future studies should include newer reanalysis, such as ECMWF's ERA-5.

The Summit Station observatory plays a critical role in evaluating space-based observations of precipitation over the GrIS. It provides independent observations of weekly snowfall accumulation via a bamboo stake field going back to 2007. Furthermore, the ICECAPS experiment provides upward-looking radar observations of precipitation since 2010 , with a likely end date of summer 2020 . The validation results in this report rely heavily on this unique dataset. In order to validate space-based snowfall estimates over the GrIS, at least one reference station over the higher GrIS should be maintained and provide routine observations of precipitation with an upward-looking radar accompanied by regular ground-based accumulation observations at reasonable temporal intervals (e.g., weekly). Currently, Summit Station is well equipped to fill this role. It is unclear if after summer 2020 radar observations will remain available at Summit.

Uncertainty in $Z-S$ relationships caused by unknown and variable microphysical properties of snowfall plays an important role over the GrIS as well as elsewhere. Over the higher GrIS in particular, snowfall appears dominated by smaller ice crystals with little riming. Consequently, we find that $Z-S$ relationships built on such particles compare better to surface observations at Summit than other $Z-S$ relationships that were devised with midlatitude snowfall in mind. Here, we apply the $Z-S$ relationships that provide a reasonable fit at Summit to the entire GrIS, which might potentially lead to biases in lower-lying regions. Further study of microphysical properties of snowfall over these regions might help address these uncertainties. Existing networks of automated weather stations such as PROMICE or GC-NET already provide limited information on snow accumulation but could be expanded to include more direct precipitation observations.

Given the validation results reported here, we are confident that space-based radar observations from CloudSat and, in the future, EarthCare (Illingworth et al., 2015) will allow for mapping of surface precipitation over the GrIS at an accuracy high enough to validate large-scale accumulation at seasonal temporal scales and spatial scales of the size of individual drainage basins. The nadir-only observation geometry of CloudSat and EarthCare hampers evaluation at finer spatial scales. Future space-based precipitation missions with scanning radars might provide even more information about snowfall over the GrIS. However, minimum detection thresholds need to be low enough for such instruments, as $50 \%$ of the precipitation falling over the high GrIS is associated with reflectivities between $-10 \mathrm{dBZ}$ and $+5 \mathrm{dBZ}$. Another important factor is that the range resolution of future radars needs to be carefully tuned so as to avoid ground clutter issues, in particular when shallow precipitation is dominant. With the above caveats, space-based radars can also help provide validation datasets for other missions, such as radar or lidar altimeter missions. If integrated over large enough temporal and spatial scales, the radar-derived precipitation accumulation adjusted for sublimation/deposition should equal the surface height change observed by altimeter to within the accuracy of the snowpack density needed to covert from liquid 
equivalent precipitation to geometric surface height change from accumulation.

Data availability. All study data are available via the European Space Agency's (ESA) campaign dataset website: https://earth.esa. int/web/guest/campaigns (last accessed: 9 June 2019) under entry SNOWSUM. In addition, ERA-Interim data are available from the University Corporation for Atmospheric Research's (UCAR) website https://rda.ucar.edu/datasets/ds627.0/ (last accessed: 9 June 2019).

Author contributions. RB, FF, and DS designed and conceptualized the study. RB performed the investigation and did all of the data analysis. CP and MDS helped analyze and interpret the ICECAPS data. RB wrote the original draft. All co-authors contributed to reviewing and editing this draft.

Competing interests. The authors declare that they have no conflict of interest.

Acknowledgements. Ralf Bennartz, Claire Pettersen, and Matthew D. Shupe were supported by NSF grants 1304544, 1314127, and 1314156. Informus $\mathrm{GmbH}$ was supported through ESA's SNOWSUM project. CloudSat observations were obtained from the CloudSat Data Processing Center. ERA-Interim data were obtained from UCAR.

Financial support. This research has been supported by the NSF (grant nos. 1304544, 1314127, and 1314156) and the ESA (SNOWSUM Project).

Review statement. This paper was edited by Jayanarayanan Kuttippurath and reviewed by Florentin Lemonnier and two anonymous referees.

\section{References}

Adhikari, A., Liu, C., and Kulie, M. S.: Global Distribution of Snow Precipitation Features and Their Properties from 3 Years of GPM Observations, J. Climate, 31, 3731-3754, https://doi.org/10.1175/jcli-d-17-0012.1, 2018.

Behrangi, A., Christensen, M., Richardson, M., Lebsock, M., Stephens, G., Huffman, G. J., Bolvin, D., Adler, R. F., Gardner, A., Lambrigtsen, B., and Fetzer, E.: Status of high-latitude precipitation estimates from observations and reanalyses, J. Geophys. Res.-Atmos., 121, 4468-4486, https://doi.org/10.1002/2015jd024546, 2016.

Berdahl, M., Rennermalm, A., Hammann, A., Mioduszweski, J., Hameed, S., Tedesco, M., Stroeve, J., Mote, T., Koyama, T., and McConnell, J. R.: Southeast Greenland Winter Precipitation
Strongly Linked to the Icelandic Low Position, J. Climate, 31, 4483-4500, https://doi.org/10.1175/jcli-d-17-0622.1, 2018.

Box, J. and Steffen, K.: Greenland Climate Network (GCNET) Data Reference, available at: http://cires1.colorado.edu/ steffen/gcnet/Gc-net_documentation_Nov_10_2000.pdf (last access: 9 June 2019), 2000.

Castellani, B. B., Shupe, M. D., Hudak, D. R., and Sheppard, B. E.: The annual cycle of snowfall at Summit, Greenland, J. Geophys. Res.-Atmos., 120, 6654-6668, https://doi.org/10.1002/2015jd023072, 2015.

Cullather, R. I., Nowicki, S. M. J., Zhao, B., and Suarez, M. J.: Evaluation of the Surface Representation of the Greenland Ice Sheet in a General Circulation Model, J. Climate, 27, 4835-4856, https://doi.org/10.1175/jcli-d-13-00635.1, 2014.

Cullen, N. J., Mölg, T., Conway, J., and Steffen, K.: Assessing the role of sublimation in the dry snow zone of the Greenland ice sheet in a warming world, J. Geophys. Res.-Atmos., 119, 65636577, https://doi.org/10.1002/2014jd021557, 2014.

Dee, D. P., Uppala, S. M., Simmons, A. J., Berrisford, P., Poli, P., Kobayashi, S., Andrae, U., Balmaseda, M. A., Balsamo, G., Bauer, P., Bechtold, P., Beljaars, A. C. M., van de Berg, L., Bidlot, J., Bormann, N., Delsol, C., Dragani, R., Fuentes, M., Geer, A. J., Haimberger, L., Healy, S. B., Hersbach, H., Hólm, E. V., Isaksen, L., Kållberg, P., Köhler, M., Matricardi, M., McNally, A. P., Monge-Sanz, B. M., Morcrette, J. J., Park, B. K., Peubey, C., de Rosnay, P., Tavolato, C., Thépaut, J. N., and Vitart, F.: The ERA-Interim reanalysis: configuration and performance of the data assimilation system, Q. J. Roy. Meteor. Soc., 137, 553-597, https://doi.org/10.1002/qj.828, 2011.

Dibb, J. E. and Fahnestock, M.: Snow accumulation, surface height change, and firn densification at Summit, Greenland: Insights from 2 years of in situ observation, J. Geophys. Res., 109, D24113, https://doi.org/10.1029/2003jd004300, 2004.

Ettema, J., van den Broeke, M. R., van Meijgaard, E., van de Berg, W. J., Bamber, J. L., Box, J. E., and Bales, R. C.: Higher surface mass balance of the Greenland ice sheet revealed by highresolution climate modeling, Geophys. Res. Lett., 36, L12501, https://doi.org/10.1029/2009gl038110, 2009.

Fausto, R. S., Box, J. E., Vandecrux, B., van As, D., Steffen, K., MacFerrin, M. J., Machguth, H., Colgan, W., Koenig, L. S., McGrath, D., Charalampidis, C., and Braithwaite, R. J.: A Snow Density Dataset for Improving Surface Boundary Conditions in Greenland Ice Sheet Firn Modeling, Front. Earth Sci., 6, 51, https://doi.org/10.3389/feart.2018.00051, 2018.

Hiley, M. J., Kulie, M. S., and Bennartz, R.: Uncertainty Analysis forCloudSatSnowfall Retrievals, J. Appl. Meteorol. Clim., 50, 399-418, https://doi.org/10.1175/2010jamc2505.1, 2011.

Hong, G.: Parameterization of scattering and absorption properties of nonspherical ice crystals at microwave frequencies, J. Geophys. Res.-Atmos., 112, D11208, https://doi.org/10.1029/2006JD008364, 2007.

Illingworth, A. J., Barker, H. W., Beljaars, A., Ceccaldi, M., Chepfer, H., Clerbaux, N., Cole, J., Delanoë, J., Domenech, C., Donovan, D. P., Fukuda, S., Hirakata, M., Hogan, R. J., Huenerbein, A., Kollias, P., Kubota, T., Nakajima, T., Nakajima, T. Y., Nishizawa, T., Ohno, Y., Okamoto, H., Oki, R., Sato, K., Satoh, M., Shephard, M. W., Velázquez-Blázquez, A., Wandinger, U., Wehr, T., and van Zadelhoff, G. J.: The EarthCARE Satellite: The Next Step Forward in Global Measurements of Clouds, Aerosols, 
Precipitation, and Radiation, B. Am. Meteorol. Soc., 96, 13111332, https://doi.org/10.1175/bams-d-12-00227.1, 2015.

Kulie, M. S. and Bennartz, R.: Utilizing Spaceborne Radars to Retrieve Dry Snowfall, J. Appl. Meteorol. Clim., 48, 2564-2580, https://doi.org/10.1175/2009jamc2193.1, 2009.

Kulie, M. S. and Milani, L.: Seasonal variability of shallow cumuliform snowfall: a CloudSat perspective, Supplement, Q. J. Roy. Meteor. Soc., 144, 329-343, https://doi.org/10.1002/qj.3222, 2018.

Kulie, M. S., Milani, L., Wood, N. B., Tushaus, S. A., Bennartz, R., and L'Ecuyer, T. S.: A Shallow Cumuliform Snowfall Census Using Spaceborne Radar, J. Hydrometeorol., 17, 1261-1279, https://doi.org/10.1175/jhm-d-15-0123.1, 2016.

Liu, G. S.: A Database of Microwave Single-Scattering Properties for Nonspherical Ice Particles, B. Am. Meteorol. Soc., 89, 15631570, 2008.

Maahn, M., Burgard, C., Crewell, S., Gorodetskaya, I. V., Kneifel, S., Lhermitte, S., Van Tricht, K., and van Lipzig, N. P. M.: How does the spaceborne radar blind zone affect derived surface snowfall statistics in polar regions?, J. Geophys. Res.-Atmos., 119, 13604-13620, https://doi.org/10.1002/2014jd022079, 2014.

Matrosov, S. Y.: Modeling backscatter properties of snowfall at millimeter wavelengths, J. Atmos. Sci., 64, 1727-1736, 2007.

Morlighem, M., Williams, C. N., Rignot, E., An, L., Arndt, J. E., Bamber, J. L., Catania, G., Chauche, N., Dowdeswell, J. A., Dorschel, B., Fenty, I., Hogan, K., Howat, I., Hubbard, A., Jakobsson, M., Jordan, T. M., Kjeldsen, K. K., Millan, R., Mayer, L., Mouginot, J., Noel, B. P. Y., O'Cofaigh, C., Palmer, S., Rysgaard, S., Seroussi, H., Siegert, M. J., Slabon, P., Straneo, F., van den Broeke, M. R., Weinrebe, W., Wood, M., and Zinglersen, K. B.: BedMachine v3: Complete Bed Topography and Ocean Bathymetry Mapping of Greenland From Multibeam Echo Sounding Combined With Mass Conservation, Geophys. Res. Lett., 44, 11051-11061, https://doi.org/10.1002/2017GL074954, 2017.

Palerme, C., Kay, J. E., Genthon, C., L'Ecuyer, T., Wood, N. B., and Claud, C.: How much snow falls on the Antarctic ice sheet?, The Cryosphere, 8, 1577-1587, https://doi.org/10.5194/tc-8-15772014, 2014.

Palerme, C., Claud, C., Wood, N. B., L'Ecuyer, T., and Genthon, C.: How Does Ground Clutter Affect CloudSat Snowfall Retrievals Over Ice Sheets?, IEEE Geosci. Remote S., 16, 342-346, https://doi.org/10.1109/lgrs.2018.2875007, 2019.

Pettersen, C., Bennartz, R., Merrelli, A. J., Shupe, M. D., Turner, D. D., and Walden, V. P.: Precipitation regimes over central Greenland inferred from 5 years of ICECAPS observations, Atmos. Chem. Phys., 18, 4715-4735, https://doi.org/10.5194/acp18-4715-2018, 2018.

Reeh, N., Fisher, D. A., Koerner, R. M., and Clausen, H. B.: An empirical firn-densification model comprising ice lenses, Ann. Glaciol., 42, 101-106, 2005.

Sheppard, B. E. and Joe, P. I.: Performance of the Precipitation Occurrence Sensor System as a Precipitation Gauge, J. Atmos. Ocean. Tech., 25, 196-212, https://doi.org/10.1175/2007jtecha957.1, 2008.

Shupe, M. D., Turner, D. D., Walden, V., Bennartz, R., Cadeddu, M. P., Castellani, B. B., Cox, C. J., Hudak, D. R., Kulie, M. S., Miller, N. B., Neely, R. R., and Neff, W. D.: High and Dry: new Observations of Tropospheric and Cloud Properties above the greenland ice Sheet, B. Am. Meteorol. Soc., 94, 169-186, 2013.

Souverijns, N., Gossart, A., Lhermitte, S., Gorodetskaya, I. V., Grazioli, J., Berne, A., Duran-Alarcon, C., Boudevillain, B., Genthon, C., Scarchilli, C., and van Lipzig, N. P. M.: Evaluation of the CloudSat surface snowfall product over Antarctica using ground-based precipitation radars, The Cryosphere, 12, 37753789, https://doi.org/10.5194/tc-12-3775-2018, 2018.

Stephens, G. L., Vane, D. G., Boain, R. J., Mace, G. G., Sassen, K., Wang, Z. E., Illingworth, A. J., O’Connor, E. J., Rossow, W. B., Durden, S. L., Miller, S. D., Austin, R. T., Benedetti, A., Mitrescu, C., and Team, C. S.: The cloudsat mission and the atrain - A new dimension of space-based observations of clouds and precipitation, B. Am. Meteorol. Soc., 83, 1771-1790, 2002.

Stephens, G. L., Vane, D. G., Tanelli, S., Im, E., Durden, S., Rokey, M., Reinke, D., Partain, P., Mace, G. G., Austin, R., L'Ecuyer, T., Haynes, J., Lebsock, M., Suzuki, K., Waliser, D., Wu, D., Kay, J., Gettelman, A., Wang, Z., and Marchand, R.: CloudSat mission: Performance and early science after the first year of operation, J. Geophys. Res.-Atmos., 113, D00A18, https://doi.org/10.1029/2008jd009982, 2008.

Tanelli, S., Durden, S. L., Im, E., Pak, K. S., Reinke, D. G., Partain, P., Haynes, J. M., and Marchand, R. T.: CloudSat's Cloud Profiling Radar After Two Years in Orbit: Performance, Calibration, and Processing, IEEE T. Geosci. Remote, 46, 3560-3573, 2008.

van As, D.: The Programme for Monitoring of the Greenland Ice Sheet: PROMICE science report 2016, Geological Survey of Denmark and Greenland (GEUS) 73, available at: https://data. geus.dk/promice/reports/PROMICE_science_report_2016.pdf (last access: 9 June 2019), 2017.

van den Broeke, M., Bamber, J., Ettema, J., Rignot, E., Schrama, E., van de Berg, W. J., van Meijgaard, E., Velicogna, I., and Wouters, B.: Partitioning recent Greenland mass loss, Science, 326, 984 986, https://doi.org/10.1126/science.1178176, 2009.

van den Broeke, M. R., Enderlin, E. M., Howat, I. M., Kuipers Munneke, P., Noël, B. P. Y., van de Berg, W. J., van Meijgaard, E., and Wouters, B.: On the recent contribution of the Greenland ice sheet to sea level change, The Cryosphere, 10, 1933-1946, https://doi.org/10.5194/tc-10-1933-2016, 2016.

Vernon, C. L., Bamber, J. L., Box, J. E., van den Broeke, M. R., Fettweis, X., Hanna, E., and Huybrechts, P.: Surface mass balance model intercomparison for the Greenland ice sheet, The Cryosphere, 7, 599-614, https://doi.org/10.5194/tc-7-599-2013, 2013.

Wood, N. B., L'Ecuyer, T. S., Heymsfield, A. J., Stephens, G. L., Hudak, D. R., and Rodriguez, P.: Estimating snow microphysical properties using collocated multisensor observations, J. Geophys. Res.-Atmos., 119, 8941-8961, https://doi.org/10.1002/2013jd021303, 2014.

Zwally, H. J., Giovinetto, M. B., Beckley, M. A., and Saba, J. L.: Antarctic and Greenland Drainage Systems, GSFC Cryospheric Sciences Laboratory, available at: http://icesat4.gsfc.nasa.gov/ cryo_data/ant_grn_drainage_systems.php (last access: 9 June 2019), 2012. 